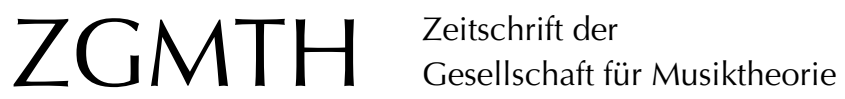

Froebe, Folker (2007): Satzmodelle des `Contrapunto alla mentes und ihre Bedeutung für den Stilwandel um 1600. ZGMTH 4/1-2, 13-55. https://doi.org/10.31751/244 (c) 2007 Folker Froebe

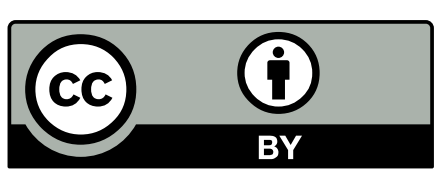

Dieser Text erscheint im Open Access und ist lizenziert unter einer Creative Commons Namensnennung 4.0 International Lizenz.

This is an open access article licensed under a

Creative Commons Attribution 4.0 International License.

veröffentlicht / first published: 01/01/2007

zuletzt geändert / last updated: 07/03/2016 


\title{
Satzmodelle des >Contrapunto alla mentes und ihre Bedeutung für den Stilwandel um 1600
}

\author{
Folker Froebe
}

Vom 15. bis 17. Jahrhundert wurde die mehrstimmige Vokalimprovisation (der >Contrapunto alla mente`) anhand sequenzieller Cantus-firmus-Modelle und imitatorischer Sequenzen gelehrt. Diese bis ins 18. Jahrhundert nachwirkende Lehrtradition erweist sich als ein theoriegeschichtlicher ımissing link: Kaum sonst in musiktheoretischen Zeugnissen wird die entwicklungsgeschichtliche Kontinuität von der Vokalpolyphonie des 15. und 16. Jahrhunderts zum ımodellgestützten` Kontrapunkt des Generalbasszeitalters so deutlich. Eine nähere Betrachtung der zentralen Quellen zwischen 1553 und 1630 lässt erkennen, dass die vokale Improvisationslehre zugleich eine implizite Theorie des konzertanten Kontrapunkts zur Verfügung stellt: Die Modelle der sequenzbasierten Improvisationsdidaktik bewahren ältere Praktiken der Generation Josquins und antizipieren (bzw. reflektieren) zugleich den `Stilwandel der musikalischen `Hochsprache` um 1600. Kompositionsgeschichtliche Schlaglichter beleuchten die Transformation der tradierten Modelle und die für den neuen Stil charakteristischen Techniken ihrer Inszenierung.

As we deepen our knowledge of the music of the past, we begin to realize that the same principles of musical organization - principles, of course, of a high degree of generality - can be found at work in music of markedly divergent styles. ${ }^{1}$

\section{Einleitung}

Sind Satzmodelle ein Gegenstand der generalisierenden Theorie oder gehören sie als konventionelle, idiomatische Wendungen einer stilbezogenen »Dogmatik ${ }^{2}$ an? Entgehen lässt sich dieser prekären Alternative nur durch eine entwicklungsgeschichtliche Perspektive, die in basalen, stilübergreifenden Satzmodellen (Struktur), ihrer zeit- oder genretypischen Auskomponierung (Stil) und ihrem bedeutungskonstituierenden `Gebrauch (Topik) zugleich strukturelle, analytisch differenzierbare Schichten zu erkennen vermag.

1 Salzer/Schachter 1969, Introduction, XV.

$2 »[\ldots]$ die Notwendigkeit, eine musikalische Topik und Dogmatik zu entwickeln, [...] ist nicht einmal gesehen, geschweige denn realisiert worden. Wenn ein künftiger Opernkomponist jenseits der sTheorie`, die er im Konservatorium studierte, am Abend im Theater durch Erfahrung und Vergleich das eigentliche Metier lernte, das er in der >Praxis` brauchte, so bewegte er sich im Umkreis dessen, was Aristoteles `Topikı nannte." (Dahlhaus 1984, 55 f.) 
In Übergangszeiten tritt die evolutionäre Verwandlung musiksprachlicher Topoi offen zu Tage. Denn das Neue ist - wie Dahlhaus betont hat - neu meist nicht durch Gegensatz oder Negation, sondern durch die manieristische Zuspitzung der alternden Hochsprache oder den Rückbezug auf eine im Laufe ihrer ästhetischen Kodifizierung abgeschliffene Expressivität. ${ }^{3}$ So erkannte Werner Braun im »Stilwandel um 1600 « zugleich einen »Umschlag von der >Musica renovata zur >Musica nova «.$^{4}$ Die Koinzidenz kompositorischer Lösungen um 1600 mit älteren, dem Contrapunto alla mente ${ }^{5}$ (also der vokalen Improvisationskunst) entstammenden Modellen ist in der Tat frappierend: Gerade jene Imitations- und Sequenzmodelle, die in der zweiten Hälfte des 16. Jahrhunderts bereits mehr oder minder als sveraltet galten, prägen die großflächige Architektur der neuen konzertanten Polyphonie. ${ }^{6}$ In manchen Madrigalabschnitten Claudio Monteverdis und in den Ritornellen und Falsobordoni der Marienvesper scheint es, als bezöge die Musik ihre kraftvolle Expressivität gerade aus der ostentativen Präsentation snackter Modelle, ihrer formbildenden Wiederholung und affektiven Aufladung durch Text und Kontext: Das Neue der ‘frühbarocken` Vokalmusik liegt weniger im Material als im Materialgebrauch, in einem Hang zu plakativer Elementarisierung und satztechnischer Ökonomie.

Die konventionelle Verfestigung, diminutive Überformung und Transformation der Basismodelle des sstile antico erwiesen sich als prägend für die musiksprachliche Entwicklung der folgenden drei Jahrhunderte. Die ızukunftsträchtigen`Werke Monteverdis sind dabei nicht zwangsläufig seine Opern und experimentell-theatralischen Madrigale, sondern gerade auch jene noch in der Tradition der sprima pratticas stehenden Vokalwerke `da cappella ${ }^{7}$, deren Neuartigkeit in der Entfaltung sequenzieller Flächen und in der bewussten Abkehr vom Varietas-Prinzip der sklassischen Vokalpolyphonie besteht.

Reflektiert wurde diese evolutionäre Erneuerung im zeitgenössischen Diskurs kaum: $\mathrm{Zu}$ sehr standen die dezidiert ımodernen Stilmittel der rezitativischen Monodie und der affektiven Dissonanzenbehandlung (von denen viele als stilgebundene Manieren bald veralteten) im Vordergrund. Die kompositorische Praxis nach 1600 mehr oder minder angemessen zu beschreiben, blieb paradoxerweise jenen Autoren vorbehalten, die in ihren Werken - abgegrenzt von der eigentlichen Kompositionslehre - den vokalen Contrapunto alla mente in der Tradition des 16. Jahrhunderts thematisierten. Dieser theoriegeschichtliche Hintergrund soll im Folgenden unter verschiedenen Gesichtspunkten beleuchtet werden.

3 Das charakteristische Merkmal, das sämtlichen Manieristen der jeweiligen `Ars Nova` gemeinsam ist, »Marenzi und Gesualdo nicht anders als Stamitz und Philipp Emanuel Bach oder später Berlioz«, sei, so Dahlhaus, »die Verschränkung von technischer Ostentation mit ins Extrem getriebener Expressivität. Die Mittel sind im Resultat nicht restlos aufgehoben; sie werden nicht verborgen, sondern eher zur Schau gestellt.« $(1978,37)$

4 Braun 1982, 71 (vgl. auch 45).

5 Zur Begriffsgeschichte vgl. Bandur 2002, 2.

6 Braun verweist auf die für das frühe 17. Jahrhundert charakteristische »Verbindung von Skala und Spielfigur«, deren »Automatismus« sich »krass vom rhapsodischen Gestus der Monodie» unterscheide: „Die als Allabreve-Polyphonie von den Neuerern um 1600 bekämpfte `Harmonie` wäre also als konzertante Polyphonie nicht nur zurückgekehrt, sondern sie hätte in dieser Form sogar das ganze neue Zeitalter geprägt: das Zeitalter des konzertierenden Stils.« $(1982,71)$

7 Im Gegensatz zu »da concertato« oder »concertato« (vgl. Koldau 2005, 340). 
Ein erster Teil (»Quellen und Traditionen«) bietet eine theoriegeschichtliche Gesamtdarstellung des smodellgestützten improvisierten Vokalkontrapunkts, einschließlich seiner Ursprünge im 15. Jahrhundert und seiner bis ins 18. Jahrhundert reichenden Rezeptionsgeschichte. Dabei wird unter anderem ein direkter Überlieferungsstrang erkennbar, der von Vincenzo Lusitano (1553) über Silverio Picerli (1630) und Athanasius Kircher (1650) bis hin zur organistischen Improvisationslehre Andreas Werckmeisters (1702) reicht. (Manche Quellen um 1700 lassen sich vor diesem Traditionshintergrund als retrospektive Kommentare zu den Ereignissen um 1600 lesen.) Ein zweiter Teil (»Modelle«) widmet sich der systematischen Darstellung von Improvisationsmodellen, wie sie vor allem in zwei zentralen Quellen zum vokalen Contrapunto alla mente (Lusitano 1553 und Scipione Cerreto 1601) mitgeteilt werden. Dabei wird deutlich, dass spätestens um die Mitte des 16. Jahrhunderts eine umfassende Lehre der imitatorischen Sequenz vorlag, deren Potentiale kompositionsgeschichtlich erst um die Jahrhundertwende voll realisiert wurden. Ein dritter Teil (»Stilwandel«) schließlich behandelt die kompositionsgeschichtliche Transformation der tradierten Modelle und die für den neuen Stil charakteristischen Techniken ihrer Inszenierung.

\section{Quellen und Traditionen}

\section{Ursprünge}

Vom 15. bis 17. Jahrhundert wurde der vokale Contrapunto alla mente auf der Grundlage ssynthetischer Cantus firmi gelehrt. Als solche dienten Skalenmodelle im Hexachordrahmen, deren übergeordneter Linienzug durch `Gegenschritte` vermittelt sein konnte. ${ }^{8}$

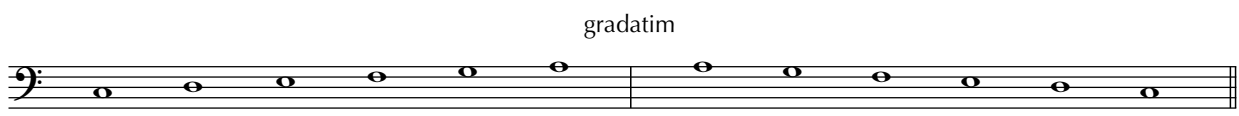

per terze (Terz-Sekund-Gegenschritt)

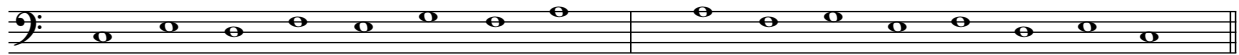

per quarte (Quart-Terz-Gegenschritt)

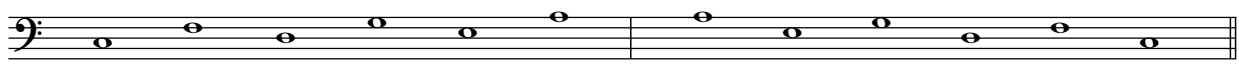

per quinte (Quintschritt)

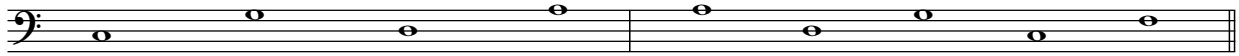

Beispiel 1: `Gegenschrittmodelle` (nach Lusitano 1553)

8 In Ermangelung eines übergeordneten, historisch vorgeformten Terminus läge es nahe, an Christian Möllers anzuknüpfen, der die entsprechenden Modelle anschaulich als »Terz-Sekund-Zickzack«, »Quart-Terz-Zickzack« etc. bezeichnete $(1989,75)$. Dass `Zickzack» »kein schönes Wort« sei, räumte schon Möllers ein. Der durch den Möllers-Schüler Volkhardt Preuß (Hamburg) eingeführte Terminus des `Zugmodells` (`Terz-Sekund-Zug` etc.) kollidiert mit schenkerianischem Sprachgebrauch. So soll hier die Rede von `Gegenschrittmodellen` (`Terz-Sekund-Gegenschrittı etc.) sein. 
Diese Modelle entstammen der Gesangsdidaktik des 15. Jahrhunderts: Mit ihrer Hilfe übten Sänger und Choristen das Solfeggieren (und Diminuieren) von Intervallschritten im Hexachordrahmen. ${ }^{9}$ Noch der kurze Traktat Scala di musica von Orazio Scaletta, der zwischen 1595 und 1698 insgesamt 31mal aufgelegt wurde, spiegelt diese alte Praxis. ${ }^{10}$

Die Gradus-Lehre (die Lehre von den kontrapunktischen Fortschreitungen) des 15. Jahrhunderts nutzte die hexachordalen Skalen- und Gegenschrittmodelle, um an ihnen die Intervallprogressionen des zweistimmigen Satzes zu exemplifizieren. ${ }^{11}$ In den Traktaten Ugolini von Orvietos ${ }^{12}$ und Johannes Hothbys ${ }^{13}$ kündigt sich ein für Jahrhunderte fortbestehendes `Basisrepertoire` an.

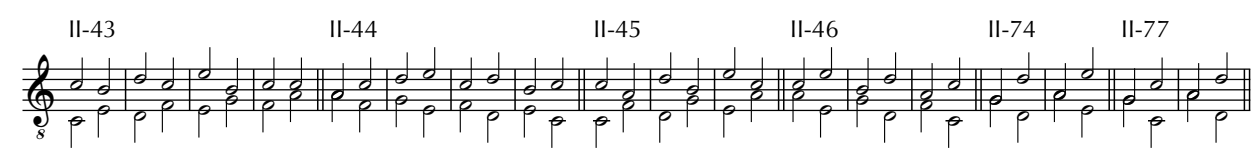

Beispiel 2: Ugolini von Orvieto 1960, II. Buch

Das seit Mitte des 15. Jahrhunderts aufkommende Interesse an imitatorischen Satztechniken dokumentiert eindrucksvoll der Hothby zugeschriebene Traktat "Spetie tenore del contrapunto prima« (vor 1487), der die wohl früheste systematische Darstellung von Kanonmodellen auf Grundlage von Skalen- und Gegenschrittsequenzen bietet: ${ }^{14}$ Das melodische Modell setzt in der Folgestimme um eine Progression verschoben ein und kontrapunktiert sich selbst in imitatorischer Gegenbewegung.

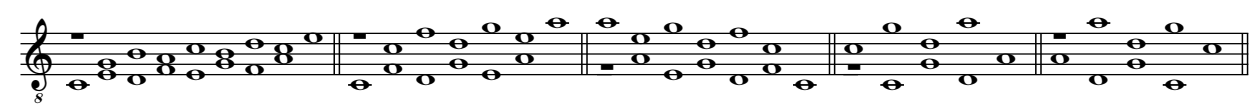

Beispiel 3: Hothby 1977, 88f., Ex. 10

9 Entsprechende Hexachord-Modelle bringt z. B. Nicolaus Listenius in seiner Musica von 1537 (vgl. von Loesch 2003, 173).

10 Die italienischen Gesangsschulen des späten 17. Jahrhunderts übernahmen die älteren hexachordalen Skalen- und Gegenschrittmodelle (die wir bei Scaletta noch in ganz traditioneller Form dargestellt finden), um an ihnen die neuen Manieren des diminutiven Kunstgesanges zu exerzieren. Die Gesangstraktate von Daniel Friderici (Musica figuralis oder Newe Unterweisung der Singe Kunst, 1619), Johann Andreas Herbst (Musica moderna prattica [...], 1653) und Johann Crüger (Musicae practicae praecepta brevia [...], 1660; alle drei Traktate in: Grampp 2006) zeugen von dem Bestreben, auch in Deutschland »auff jezige Italienische Manier zu singen « (Herbst), und folgen streng der tradierten Systematik fallender und steigender Gänge; Daniel Speer (Musicalisches Kleeblatt, 1697) bezieht auch Septimensprünge ein. Eine nach wie vor relevante Gesamtdarstellung findet sich bei Goldschmidt 1892.

11 Sachs verweist auf den »engen Konnex zwischen Contrapunctus-Lehre und Solmisationspraxis» (1984, 208).

12 Ugolini von Orvieto 1960, II, Kap. 6-26.

13 Hothby 1977, »Tractatus de arte contrapunti«, Kap. 8-11.

14 Ebd, 88f., Ex. 10. Wie Sachs feststellte, ist Reaneys synkopische Deutung »fragwürdig« (1984, 199). Erst im folgenden Abschnitt (90f., Ex. 11) gibt Hothby tatsächlich Beispiele für die sfuga syncopataく. 
Die kontrapunktische Sequenz scheint von Hothby bereits als ein der elaborierten Imitation vorgeordnetes Fortschreitungsmodell verstanden worden zu sein (was vor dem Hintergrund der in der Gradus-Lehre verwendeten sequenziellen Schemata nahe liegt). Dass Gegenschrittmodelle zugleich auch der >Mechanikı instrumentalen Improvisierens entgegenkamen, spiegeln Traktate zur Orgelimprovisation seit Mitte des 15. Jahrhunderts. ${ }^{15}$

\section{Verschriftlichung mündlicher Traditionen: Quellen zum Contrapunto alla mente zwischen 1553 und 1588}

Die sequenziellen Hexachord-Modelle der Graduslehre und die aus ihnen entwickelten kanonischen Sequenzen spielten in den musiktheoretischen Schriften der ersten Hälfte des 16. Jahrhunderts keine Rolle mehr - möglicherweise, weil sie allzu offenkundig im Widerspruch zum Varietas-Prinzip standen. In der mündlich-praktischen Lehrtradition des vokalen Contrapunto alla mente jedoch dienten die hexachordalen Skalen- und Gegenschrittmodelle weiterhin als ssynthetische`Cantus firmi: Die auf ihrer Grundlage gewonnenen kontrapunktischen Modelle sollten es dem Lernenden erleichtern, »Praxis in dieser Art von Kontrapunkt zu erlangen und andere [Fugen] zu finden ${ }^{16}$, also das erlernte Repertoire auf ıreal existierende`Cantus firmi zu übertragen. In der Praxis des 'cantare super librum ${ }^{17}$ interpretierte man jeden Cantus firmus "als eine Abfolge von Segmenten, die diesen verschiedenen >Patterns entlehnt wurden $«{ }^{18}$ Zarlino demonstriert das Verfahren in den Istitutioni harmoniche anhand zweistimmiger Kanons im Einklang über dem in der Unterstimme liegenden Hymnus Veni creator spiritus. ${ }^{19}$ Als strukturelles und ästhetisches Phänomen war die Sequenz also nicht das Ziel der Lehre, sondern ihr `Nebenproduktı. Doch muss die Vokalimprovisation über Skalen- und Gegenschrittmodelle in den Sängerschulen des späten 15. und des 16. Jahrhunderts intensiv praktiziert worden sein, und es ist kaum vorstellbar, dass diese Schulung ohne Auswirkungen auf die kompositorische Praxis geblieben sein sollte. Jedenfalls weisen die Sequenzmodelle

15 Im »Fundamentum Wolffgangi de nova domo«(Fundamentum des Wolfgang von Neuhaus) der Hamburger Handschrift (Mitte 15. Jahrhundert) und dem bekannteren »Fundamentum organisandi« Conrad Paumanns (1452) liegt der Cantus firmus als (bei Paumann bisweilen leicht diminuierter) 'cantus planus` im Tenor und wird durch den Diskant mit »lebhaftem Figurenwerk« (Apel 1967, 45) kontrapunktiert. Systematisch durchgeführt sind allein die Gegenschrittmodelle des Tenors: Auf den » 'ascensus et descensus simplex folgt ıascensus et descensus per tertias`, ‘quartas` und sper quintas« (ebd.). Das »Fundamentum sive ratio vera» des Hans Buchner (ca. 1520) schließlich bringt die Modelle bereits in enger kanonischer Führung.

16 »Et per che il canto fermo si puo fugare in tanti modi, che quasi farebbe impossibile rasentare pure una minima parte, si farà mentione solamente di alcune fugae, che farano piu facili all'acquistare la prattica di questa sorte Contrapunto e ritrovarne dell'altre.« (Tigrini 1588, IV, Kap. 12, 116)

17 So bezeichnet Tinctoris anschaulich die vokale Gruppenimprovisation über den im Chorbuch fixierten Cantus firmus (vgl. Sachs 1983, 169 sowie $181 \mathrm{ff.}$.).

18 »[...] any CF could be interpreted as a succession of segments sborrowed from these different patterns." (Schubert 2002, 514)

19 Zarlino 1573, III, Kap. 63, 305 ff.; vgl. Rempp, 206f. Eine systematische Darstellung der zugrunde liegenden Modelle, etwa nach dem Muster Lusitanos, bringt Zarlino nicht. Angeregt durch Zarlinos Vorbild sind Sweelincks »Unterschiedliche Exempel von Contrapunkt über den Hym[n]en `Veni Creator Spiritus` à 3《 (Sweelinck 1901, 72 ff.). 
der Improvisationsdidaktik auf ein Stück kompositorischer Wirklichkeit, das in der Kompositionslehre des 16. Jahrhunderts ansonsten ohne Reflex geblieben ist.

Drei zentrale Quellen zum Contrapunto alla mente erschienen Mitte des 16. Jahrhunderts binnen eines einzigen Jahrzehnts. Sie zeugen von einer »vergangenen Virtuosität « ${ }^{20}$ der Vokalimprovisation. Der Nutzen der Lehre vom Contrapunto alla mente für die Kompositionspraxis wurde von den Theoretikern durchaus angesprochen ${ }^{21}$, und auch die weitverbreitete Kritik an der Fehlerhaftigkeit improvisierter Kontrapunkte (etwa bei Nicola Vicentino und Orazio Tigrini) lässt sich als Hinweis verstehen, dass die Improvisationsmodelle nicht zuletzt ihres Wertes für die Komposition wegen mitgeteilt wurden. ${ }^{22}$

Nicola Vicentino bringt 1555 in seiner Schrift L'antica musica ridotta alla moderna prattica einen kurzen, nur eine knappe Druckseite umfassenden Textabschnitt zu den »Modi di comporre alla mente sopra di canti fermi«, der ohne systematischen Anspruch gängige Praktiken referiert. ${ }^{23}$ Das einzige Kanonmodell, das Vicentino anspricht, beruht auf steigenden Quart-Terz-Gegenschritten (vgl. Beispiel 17, S. 32).

Gioseffo Zarlino stellt in den Ausgaben der Istitutioni harmoniche ab 1563 Cantusfirmus-gebundene Kanontechniken in großer Breite dar, ohne sich auf das didaktische Modell sequenzieller Gegenschritte zu stützen. ${ }^{24}$ Er gibt stattdessen Regeln für die Kontrapunktierung einzelner Intervallprogressionen; Satzmodelle lassen sich, wie Rempp demonstriert ${ }^{25}$, aus den Notenbeispielen extrahieren.

Den eigentlichen Ausgangspunkt einer bis ins 18. Jahrhundert zu verfolgenden Lehrtradition des Contrapunto alla mente auf Grundlage sequenzieller Cantus firmi bildet die Introduttione facilissima et novissima di canto fermo, figurato, contrapunto semplice, et in concerto (Rom 1553) des gebürtigen Portugiesen Vicenzo Lusitano. ${ }^{26}$ Der zweite Teil des rein praxisbezogenen ${ }^{27}$, mit nur 24 Doppelseiten ungemein knapp gefassten Traktats ist der systematischen Darstellung des improvisierten Vokalkontrapunkts gewidmet. Carl Dahlhaus referierte drei der bei Lusitano dargestellten Formen der Vokalimprovisation ${ }^{28}$,

20 Mário de Sampayo Ribeiro, Artikel »Lusitano« in: MGG 1960.

21 »[...] non solamente volendoli fare à mente; ma acciò che etiandio [sapendoli] accommodar li possino nelle lor Compositioni« (Zarlino 1573, III, Kap. 63, 317).

22 Wie bereits Vicentino (dessen Ausführungen er paraphrasiert) ist auch Tigrini der Auffassung, der wahre Kontrapunkt über einen Cantus firmus sei der Geschriebene, denn salla mente، sei es so gut wie unmöglich, nicht unendlich viele Fehler zu machen: »Ma il vero contrapunto sopra il canto fermo si è, quando prima si fa scritto: perche in quello, che si fa alla mente, è quasi impossibile, che non si facino infiniti errori.« (1588, IV, Kap. 11, 116)

23 Vicentino 1555, IV, Kap. 23, 80. Wie Lusitano beschreibt auch Vicentino fauxbourdonartige Fakturen (Dezimensatz und 6-5-Synkopation) sowie die Praxis, zu einem Cantus firmus sich wiederholende »passaggi« zu bilden.

24 Zarlino 1573, III, Kap. 63, $305 \mathrm{ff}$.

25 Rempp 1989, $206 \mathrm{f}$.

26 Theoriegeschichtlich ist Lusitano vor allem als Widerpart Nicola Vicentinos vermerkt, dessen These, die moderne Musik sei (im Sinne einer Wiederbelebung der antiken Genera) diatonisch-chromatischenharmonisch gemischt, er in einer Disputation 1551 erfolgreich entgegentrat (vgl. Rempp 1989, 74).

27 »[...] solo per esto effetto di prattica« (Lusitano 1553, Vorwort).

28 Neben der zweistimmigen "aria de cantar il contrapunto«, die auf das Finden diminutiver melodischer Formeln oder Soggetti zu einem Cantus firmus zielt, erläutert Dahlhaus den dreistimmigen 
ließ jedoch Lusitanos Ausführungen zur engen Imitation sequenzieller Cantus firmi (»fugare il canto « $)^{29}$ sowie zur Kontrapunktierung des Cantus firmus durch zwei- bis dreistimmige Kanonbildungen (»Fughe sopra il canto «) ${ }^{30}$ unberücksichtigt. Gerade in diesen Teilen des Traktats behandelt Lusitano das Phänomen der kontrapunktischen Sequenz systematisch und mit einer Breite des Modellrepertoires wie kein Autor vor ihm. ${ }^{31}$

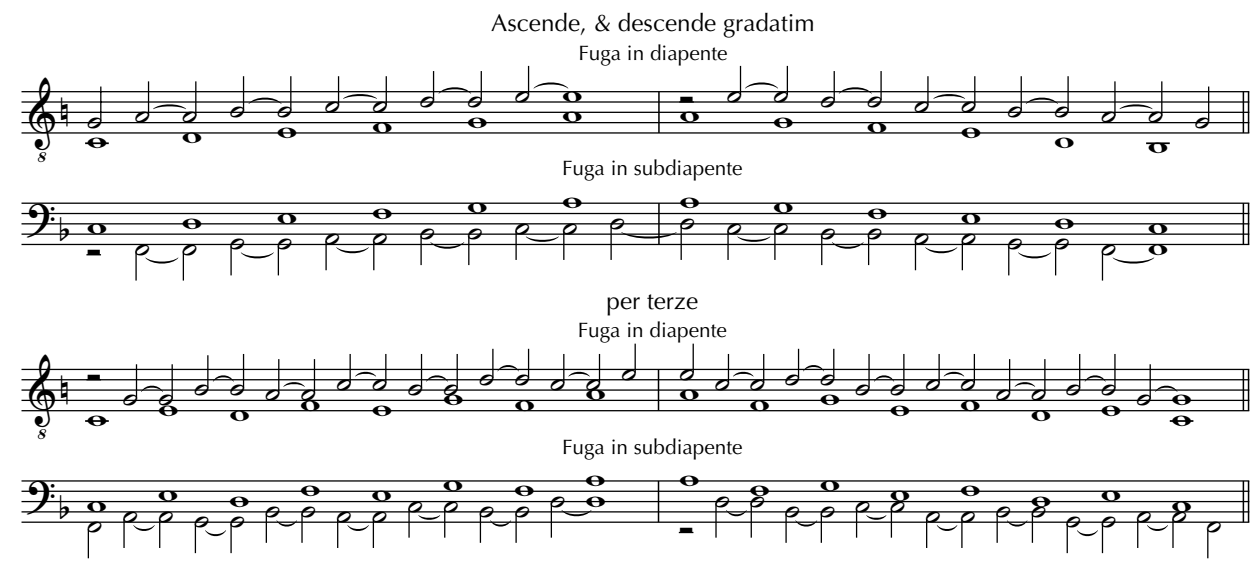

per quarte

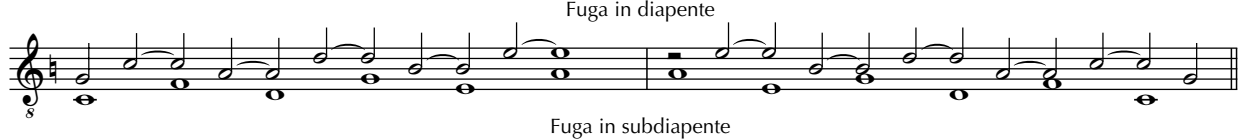

Fuga in subdiapente

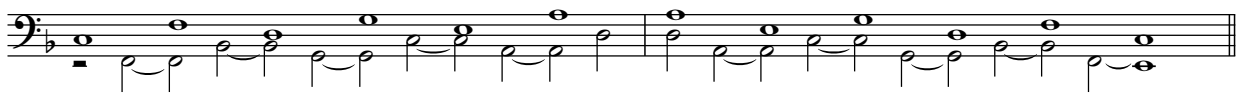

per quinte

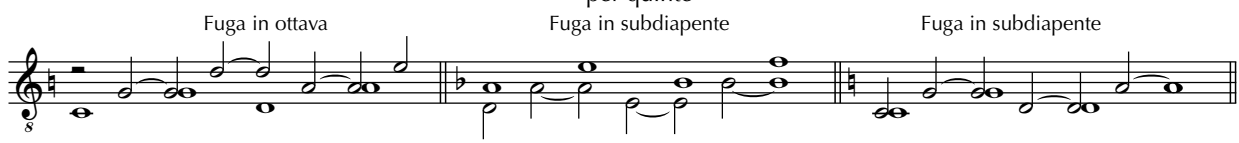

Beispiel 4: Lusitano 1553, 13 f., »fugare il canto fermo « ${ }^{32}$

"contrapunto in concerto", der in der Tradition des Gymel auf dem Dezimensatz der Außenstimmen beruht, sowie den drei- bis vierstimmigen "contrapunto in accordo", dessen Oberstimmensatz sich nicht am Cantus firmus selbst, sondern an seiner Bassfundierung ausrichtet (1959, 163-167). Eine Gesamtdarstellung des Traktats gibt Apfel 1981, 166-172.

29 Lusitano 1553, $13 \mathrm{f}$.

30 Ebd., 17-20.

31 Teilweise wurden die bei Lusitano beschriebenen Techniken »engerer Imitation oder zwei- und mehrstimmiger Kanons" erst Vicentino und Zarlino zugeschrieben (Laubenthal/Sachs 1989/90, 170; ebenso Rempp 1989, 206); Braun meinte, »den ersten Anstoß « habe Tigrini 1588 gegeben (1994, 272 f.).

32 Beispiel 4 folgt in einigen Details der Fassung Tigrinis (1588, IV, Kap. 11, 120 ff.); sowohl bei Lusitano als auch Tigrini fehlen in diesem Zusammenhang Modelle auf der Grundlage fallender Quintschritte. 
Für die Imitation sequenzieller Cantus firmi gibt Lusitano im Textteil alternative Einsatzabstände der Kanonstimmen an (»mezza battuta, ouer [= overro] una«) und verweist damit auf die Möglichkeit, die Modelle auch im Satz `Note gegen Note` zu führen. Zu seinen insgesamt 56 Kanonmodellen »sopra il canto « (die meisten davon steigend und fallend) teilt Lusitano nur das jeweilige Konsonanzenschema und die Einsatzabstände der Folgestimmen mit; Notenbeispiele wurden von späteren Autoren (insbesondere Picerli 1630), die sich auf Lusitanos Fundus bezogen, snachgereicht‘.

Orazio Tigrini schließlich greift in seinem Compendio della musica von 1588 auf ältere Quellen zum Contrapunto alla mente zurück und paraphrasiert zunächst Vicentinos knappe Ausführungen. ${ }^{33}$ Lusitanos Abschnitt zum "fugare il canto« überträgt er weitgehend unverändert in Partitur. ${ }^{34}$

Singulär blieb Tomás de Santa Marías instrumentale Improvisationslehre Libro Llamado arte de taner fantasía von 1565. Santa María stellt drei- und vierstimmige Modellkomplexe auf Grundlage der tradierten Cantus firmi detailliert von der Spielpraxis am Tasteninstrument her dar und legt damit zugleich Denkweisen offen, die auch in der vokalen Kompositionspraxis eine Rolle gespielt haben dürften (vgl. Beispiel 12, S. 29). ${ }^{35}$ Erst über ein Jahrhundert später findet sich bei Spiridionis a Monte Carmelo, Georg Muffat und Andreas Werckmeister Vergleichbares.

\section{Renaissance des improvisierten Vokalkontrapunkts: Quellen zwischen 1601 und 1650}

Nach Lusitano (1553), Vicentino (1555), Zarlino (1563) und Santa María (1565) scheint (abgesehen von Tigrinis unambitionierter Kompilation) das Interesse der Musiktheoretiker am Contrapunto alle mente für Jahrzehnte erlahmt zu sein. Erst nach der Jahrhundertwende erschienen im Abstand jeweils einer Dekade drei große musikpraktisch ausgerichtete Schriften (Cerreto 1601, Zacconi 1622 und Picerli 1630), die dem improvisierten Vokalkontrapunkt erneut breiten Raum einräumen. Vordergründig mag dies für ein Wiederaufleben der vokalen Improvisationskunst (und ihre Bereicherung um die Techniken des diminutiven Ziergesanges) zu Beginn des 17. Jahrhunderts sprechen. Doch spiegelt das neue Interesse zugleich eine Verschiebung des kompositionstechnischen und ästhetischen Kontextes der vokalen Improvisationslehre: Das ehemals didaktisch motivierte Übungsmaterial der (imitatorischen) Sequenz war mittlerweile zu einem zentralen Gegenstand kompositorischen Interesses geworden, und die Kluft zwischen Improvisation und Komposition war ebenso im Schwinden begriffen wie die Grenze zwischen Vokalem und Instrumentalem.

Einen Neuanfang machte Scipione Cerretos Della prattica musica vocale et strumentale von 1601 mit einer umfänglichen und inhaltlich gewichtigen Improvisationslehre auf Basis sequenzieller Cantus firmi. Ludovico Zacconi übertrug im zweiten Teil seiner Prattica di musica von 1622 Cerretos Notenbeispiele (insbesondere auch die bei Cerreto einstimmig notierten Kanons) ohne substantielle Veränderungen in Partitur. Cerreto wie-

33 Tigrini 1588, IV, Kap. 11, 115.

34 Ebd., 116-123.

35 Santa María 1565, II, Kap. 17-27. 
derholt im Kern Lusitanos Zweiteilung: ${ }^{36}$ Im ersten Teil »Del Contrapunto solo sopra il Canto Fermo per sopra, \& sotto ${ }^{37}$ demonstriert er modellhafte Kontrapunktierungen des Cantus firmus. Den Ausgangspunkt bildet in der Mehrzahl der Beispiele die synkopierte Kanonbildung zum Cantus firmus, die schrittweise in Diminutionen aufgelöst wird (vgl. Beispiel 5 links). Im zweiten Teil »Del Contrapunto in Canone sopra il Canto fermo, per sopra, e sotto ${ }^{38}$ kontrapunktiert Cerreto den Cantus firmus durch zweistimmige Kanons, wiederum mit schrittweise zunehmender Diminution der Kanonstimme (vgl. Beispiel 5 rechts).
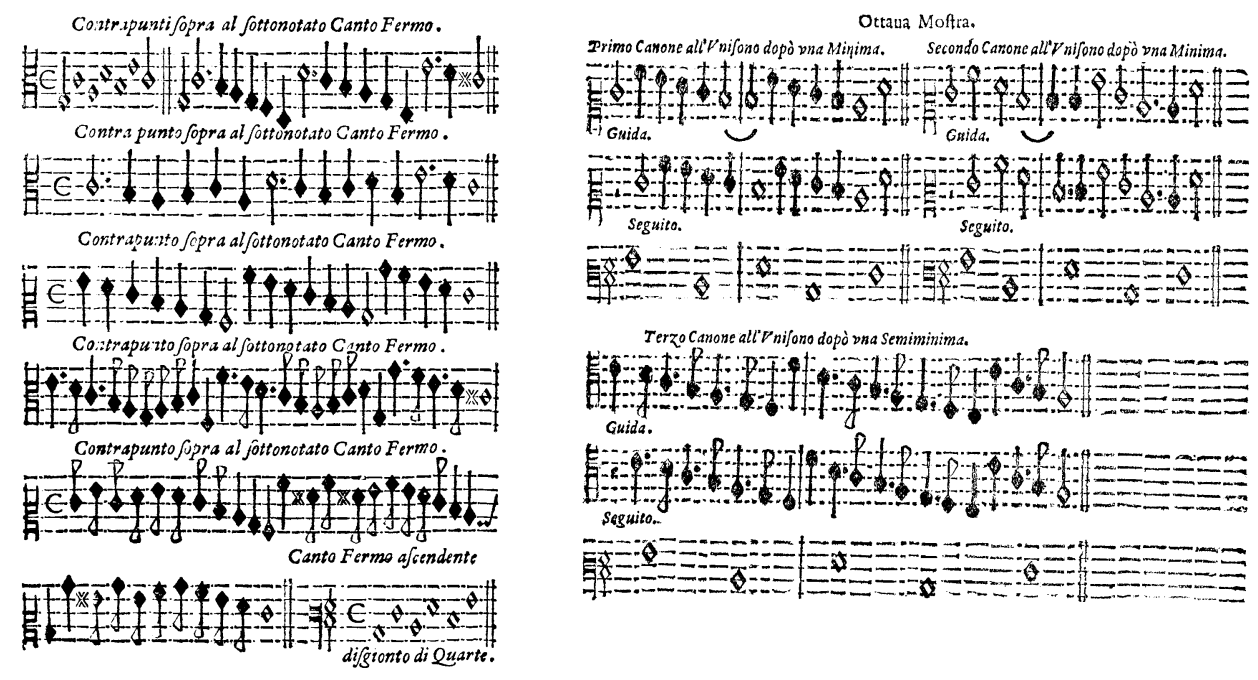

Beispiel 5: links: Cerreto 1601, 280; rechts: Zacconi 1622, 190 (nach Cerreto 1601, 285)

Silverio Picerli schließlich orientierte sich in seinem Specchio seconda di musica von 1630 so eng am Vorbild Lusitanos (in seiner Autorenliste erwähnt er außerdem Vicentino, Zarlino und Cerreto), dass sein Kapitel in weiten Teilen einer kommentierten Übertragung der stichwortartigen Anweisungen Lusitanos zu den »Fughe sopra il canto" in Notenbeispiele gleichkommt - eine Abhängigkeit, die meines Wissen bislang nicht registriert wurde.

Athanasius Kircher übernahm Picerlis Kanonlehre praktisch unverändert in seine enzyklopädische Musurgia von 1650. ${ }^{39}$ Mit Kircher endet knapp 100 Jahre nach Lusitano die schriftliche Lehrtradition einer auf Satzmodellen beruhenden Vokalimprovisation.

36 Cerreto führt in seiner Autorenliste unter anderem auch Vicentino, Zarlino und Tigrini, nicht aber Lusitano. Eine Abhängigkeit von Lusitano muss, trotz einiger in der `Natur der Sache` liegender Überschneidungen, nicht vorliegen.

37 Cerreto 1601, IV, Kap. 4, $271 \mathrm{ff}$.

38 Ebd., Kap. 5, $281 \mathrm{ff}$.

39 Kircher 1650, Bd. 1, V, Kap. 19, 368-383 sowie 389-393. 
Zugleich vermittelte Kirchers weitverbreitetes Werk die Rezeption der Kanonmodelle Lusitanos bis weit ins 18. Jahrhundert hinein.

Die Beiträge Rocco Rodios ${ }^{40}$ und Angelo Berardis ${ }^{41}$ zur Kanonlehre sind wegen ihres Verzichts auf sequenzielle Cantus firmi für unsere Fragestellung von geringem Interesse.

Die Sequenz wird theoriefähig: Kontrapunkttraktate des 17. Jahrhunderts

Ab Mitte des 17. Jahrhunderts wurden die Satzmodelle des improvisierten Kontrapunkts in die eigentliche Kompositionslehre aufgenommen. Johann Andreas Herbst bringt in seiner Musica poetica von 1643 unter anderem Beispiele für die »Ketten mit Tertien und Secunden« und »durch die Quart und Terz« mit der für die älteren Quellen charakteristischen synkopierenden Imitation. ${ }^{42}$

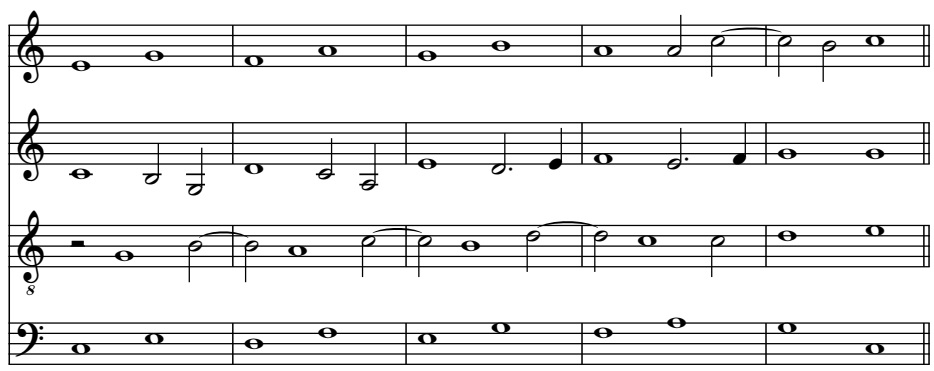

1. Ist eine Ketten mit Tertien und Secunden, eine um die andere über sich ziehend / und eine Manier gleich einer Fugen, oder imitation, so anmuthig zu hören ist [...].

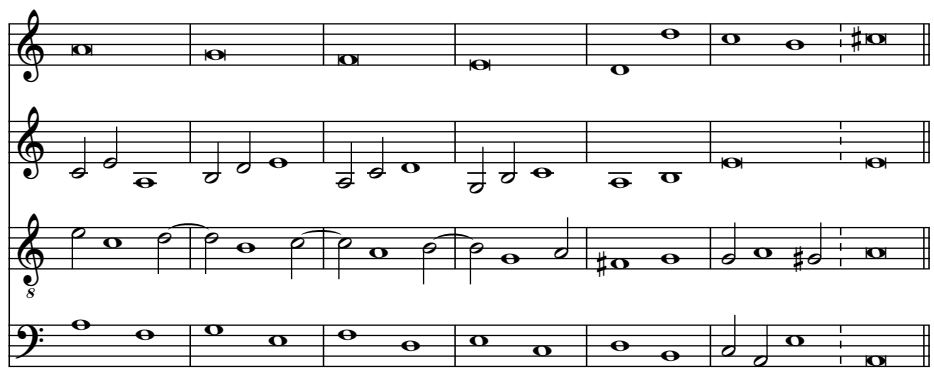

2. Ist eine Ketten abwärts / und ist eben wie die vorhergehende.

Beispiel 6: Herbst 1643, 90

Die Art und Weise, in der die alten Modelle - auch ohne im Einzelnen hergeleitet oder benannt zu werden - in die praxisbezogene Kompositionsdidaktik des späten 17. Jahrhunderts einbezogen werden konnten, zeigt sich an vielen Stellen etwa bei Giovanni

40 Rodio 1609.

41 Das II. Buch der Documenti armonici (Berardi 1687, 86-132) handelt von »Canoni, \& altri Componimenti artificiosi « und bietet eine ambitionierte Kanonlehre auf Grundlage synthetischer Cantus firmi.

42 Herbst 1643, $90 \mathrm{f}$. 
Maria Bononcini (1673), Lorenzo Penna (1684), Angelo Berardi (1687/89) und Zaccaria Tevo (1706). Der Ort des Modells ist nunmehr das (oft nur spärlich erläuterte) Beispiel, das die zuvor gegebenen Regeln auf engem Raum kontextuell umsetzt. Synkopierte Gegenschrittkanons dienten zudem seit Adriano Banchieri häufig der Darstellung des synkopierenden Kontrapunkts als einer rhythmischen `Gattung ${ }^{4}{ }^{43}$

\section{Die legitimen Erben, Teil 1: Organistische Improvisationslehre}

Eine letzte, späte sSumma des Contrapunto alla mente und zugleich ein bedeutendes Zeugnis der deutschsprachigen Kircher-Rezeption ${ }^{44}$ ist die «Zugabe oder Anhang vom gedoppelten Contrapunct und fugis ligatis « in Andreas Werckmeisters Harmonologia musica von 1702. ${ }^{45}$ Werckmeister baut zunächst die enge kanonische Führung der alten Hexachord-Modelle im Satz `Note gegen Note` durch Mixturenanlagerung bis zur vierstimmigen Einsatzfolge aus: ${ }^{46}$

Darnach nehme ich zu den obern beiden Stimmen wieder lauter Tertien und gehe mit den untersten beyden in Motu Contrario, also daß unten lauter Tertien / und oben lauter Tertien bleiben / das ist also der Schlüssel zu allerhand Arten von den Canonibus und gedoppelten 3. und 4. fachen Contrapuncto. ${ }^{47}$

Auf die imitatorische Verselbständigung der Stimmen folgt zuletzt die diminutive Individualisierung des bis dahin noch gleichsam anonymen Gerüstsatzes (Beispiel 7, S. 24)

Werckmeister verglich seine »Methode der Composition« mit dem »Ey« des »Columbo«, und seine ganze Vorrede zeugt von dem großen Stolz, erstmals explizit und systematisch den Zusammenhang von imitatorischer Sequenz, Mixturenanlagerung und doppeltem Kontrapunkt dargestellt zu haben. ${ }^{48}$ Mit Werckmeisters Kanonlehrgang ist

43 So illustriert Banchieri seine Ausführungen über die "Sincope maggiori et minori« durch eine steigende Sequenz aus Quart-Terz-Gegenschritten sowie durch einfache Synkopenketten (1614, 43). Berardi schließlich erweist sich hinsichtlich der systematischen Behandlung rhythmischer Modelle als Wegbereiter des >Gattungskontrapunkts`.

$44 \mathrm{Vgl}$. Braun 1994, $272 \mathrm{ff}$.

45 Werckmeister 1702, $95 \mathrm{ff}$. Werckmeisters Gliederung folgt der Tradition: Zunächst thematisiert er Mixturkanons aus einfachen Stufengängen sowie die fauxbourdonartige sfuga syncopatar. Es folgen Kanons auf der Grundlage melodischer Gegenschrittmodelle im Hexachordrahmen und schließlich Kanons »auf ein gewisses Subjectum«, d. h. über einem Cantus firmus (116ff., § 192).

46 Die Lehre vom doppelten Kontrapunkt war traditionell mit dem Dezimensatz verbunden; neu bei Werckmeister ist die systematische Übertragung des Verfahrens auf die imitatorische Sequenz. Friedrich Wilhelm Marpurg verfolgt in seiner Abhandlung von der Fuge (1753) diesen Ansatz konsequent weiter: Seine Lehre vom doppelten bzw. mehrfachen Kontrapunkt beschreibt im Kern nichts anderes als die Technik der Mixturenanlagerung an zweistimmige sequenzielle Gerüstsätze und die durch sie entstehenden neuen Konstellationen zwischen Stimmenpaaren. Entsprechende Darstellungen finden sich auch bei Scheibe, Spiess, Kirnberger und Riepel.

47 Werckmeister 1702, § 175, 131.

48 Ebd., $95 \mathrm{f}$. Werckmeisters Klage, »viele Musici« seien »heimlich und rahr mit ihren Wissenschafften", er aber habe seine "Methode, Vorthe[i]l und Handgriffe meinen Nechsten mitzutheilen / kein bedencken tragen wollen« (ebd.), lässt sich vielleicht als ein Hinweis auf exklusive, mündlich-praktische Lehrtraditionen verstehen. 
die Transformation des Contrapunto alla mente zur organistischen Improvisationslehre vollzogen: Die Sequenz ist als kompositionstechnisches und ästhetisches Phänomen sui generis gemeint. ${ }^{49}$ Damit vollzieht Werckmeister jenen Wandel nach, der kompositionsgeschichtlich bereits ein Jahrhundert zuvor stattgefunden hatte.

Und zwar erstlich Also kan dieses Thema in schlecht [schlicht]: einen Canonem gesetzet werden $[\ldots]$ :
Dieses Thema wollen wir nun versuchen / wie es fället / wann es in einige Transitus und Colores verändert wird.

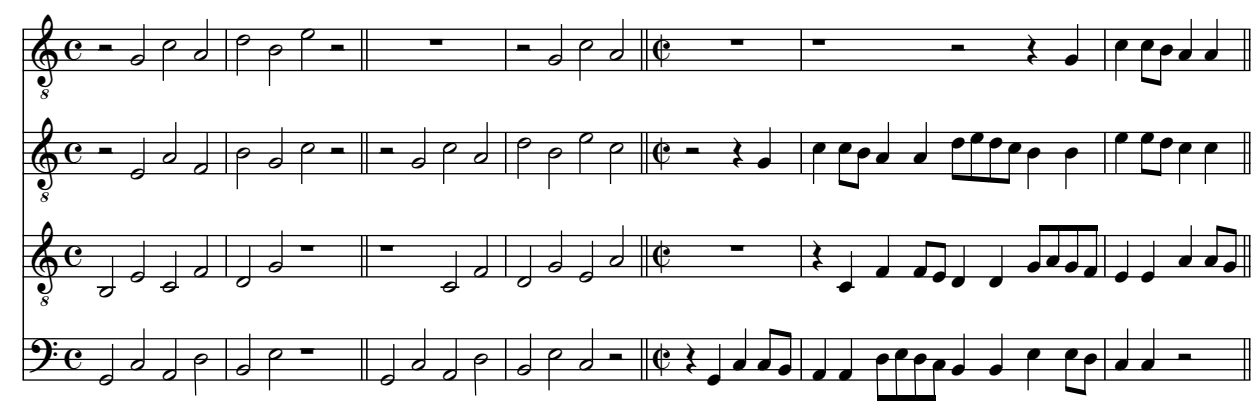

Beispiel 7: Werckmeister 1702, 131, § 210, Beispiele gekürzt

\section{Die legitimen Erben, Teil 2: Generalbass und Partimento}

Im >contrappunto alla mente verlagert sich der cantus firmus auf die Baßstimme [...]. Vor dem Hintergrund jener Tradition des Improvisierens mitsamt seiner ausgefeilten, in der Instrumentalmusik längst verselbständigten Verfahren der Systematisierung von Konsonanzen und Verzierungstönen über einer gegebenen Baßstimme war der Schritt zur Generalbaßpraxis bruchlos abzuleiten. ${ }^{50}$

Erstaunlicherweise wurden sequenzierende Bassmodelle in den überlieferten Generalbasstraktaten erst um die Wende zum 18. Jahrhundert systematisch behandelt, wenngleich anzunehmen ist, dass ihnen in der praktischen Unterweisung seit Anbeginn große Bedeutung zukam. ${ }^{51}$ Ein eindrucksvolles Zeugnis für das Weiterleben der dem Contrapunto alla mente entstammenden Modelle in der kontrapunktisch-figurativen Generalbasspraxis des 17. Jahrhunderts geben Georg Muffats »Regulae concentuum partiturae ${ }^{52}$,

49 Das Sequenzprinzip ist die Grundvoraussetzung für Werckmeisters Kanonlehre: »Es müssen aber die Intervalla gleiche Gradus und gleiche Mensur behalten« (1702, 97, § 169), ebenso müsse ein "Subjectum«, darauf man einen "Canonem machen« wolle, »in einerley Mensur und Valor fortgehen« und »in gleichen Intervallis« procedieren (116, § 192).

50 Laubenthal und Sachs 1989/90, 170.

51 Von einer elementaren auf Skalen- und Gegenschrittmodellen basierenden Generalbassdidaktik zeugen die »Exempla auf den Bassum Continuum« von Friedrich Emanuel Praetorius (Praetorius 1961). Eine bedeutende Quelle für die instrumentale Improvisationsschulung auf Grundlage sequenzieller Bassmodelle ist die nova instructio von Spiridionis (1670).

52 Die einzige erhaltene Abschrift ist auf 1699 datiert. 
die überdies noch den Vorzug besitzen, nicht allein den bezifferten Bass, sondern durchweg auch dessen exemplarische Realisierung mitzuteilen. Die satztechnische Grundlage bildet für Muffat der dreistimmige Satz, der freilich bis zur Achtstimmigkeit angereichert werden kann. Der zweite Teil des Traktats (»Exempla der vornehmsten Grieffen der Partitur «) behandelt in einem ersten Abschnitt systematisch die sequenziellen Bassfortschreitungen, wobei der Satz sich zunächst auf Grundakkorde beschränkt. ${ }^{53}$ Es folgen exemplarische Behandlungen des Sextakkordes und des Quintsextakkordes (teilweise wiederum auf Grundlage von Sequenzen) sowie die Erläuterung verschiedener Kadenzformen.

Vorzugsweise führt Muffat die Oberstimme in sprungweiser bzw. imitatorischer Gegenbewegung zum Bass (eine Praxis, die manche deutsche Generalbassquellen bis ins späte 18. Jahrhundert fortschreiben); mehrfach bildet er Oberstimmenkanons. Deppert nimmt an, bei Muffats »Exempla« habe es sich »wohl mehr um eine Art Trainingsmaterial «54 gehandelt, doch formuliert Muffat bereits im Titel ausdrücklich einen ästhetischen Anspruch: »[...] wie selbe auffs cantabliste zu vernehmen sind«. Was Muffat unter skantabek versteht, geht aus seinen Kommentaren klar hervor: "Schlechte Manier, so nichts Arioses ${ }^{55}$ bezieht sich auf einen bewegungsarmen, sekundweise schreitenden Oberstimmensatz, während der Kommentar »Haubt schöne Sprüng « ${ }^{56}$ einer Oberstimme in Quintschritten gilt. Deutlicher könnte der Gegensatz zum französischen Ideal eines durch Liegetöne abgebundenen sakkordischen` Oberstimmensatzes kaum sein!

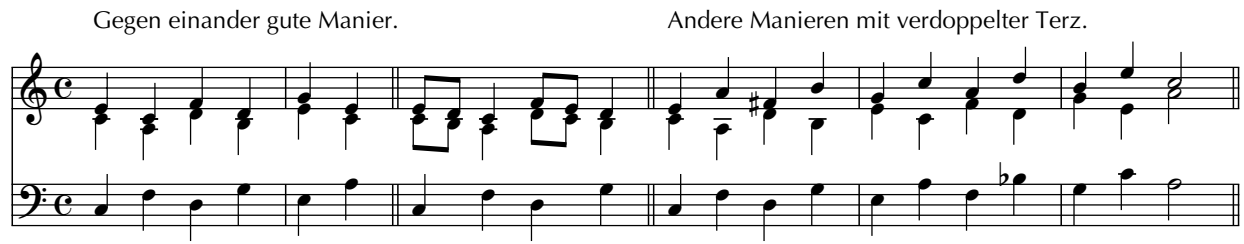

Beispiel 8: Muffat 1699, $70 \mathrm{ff}$.

Unverkennbar steht Muffats Traktat an einer historischen Schnittstelle: Während er einerseits den ganzen Reichtum lizenziöser Dissonanzenbehandlung um 1700 zeigt (insbesondere im ersten Teil, der sich der Behandlung verschiedener Signaturen widmet), ist in ihm zugleich eine Vielzahl kontrapunktischer Fortschreitungsmodelle bewahrt, die im Zuge der Verengung des Repertoires auf kadenziell interpretierbare Progressionen (Quintschritte, 'Dur-Moll-Parallelismen des 18. Jahrhunderts an Bedeutung verloren. So sind Muffats »Regulae« nicht allein ein bedeutendes Dokument der Generalbass- und Improvisationspraxis im 17. Jahrhundert, sondern auch ein wahres Kompendium (früh-)barocker Satzmodelle.

53 Muffat 1699, 56-78 (Seitenzahlen des Manuskripts).

54 Deppert 1993, 166.

55 Muffat 1699, 70.

56 Ebd., 67. 
Muffats Systematik nahe steht die neapolitanische Partimento-Tradition, in der sich um 1700 ältere Traditionen fauxbourdonartiger Oktavregeln mit den melodischen Modellen des vokalen Solfeggierens zu einer umfassenden Dogmatik kadenzieller und sequenzieller Stufengänge (und der ihnen inhärenten Bezifferungsmodelle und -varianten) verbanden. Noch in Fedele Fenarolis Regole von 1775, die weit ins 19. Jahrhundert ausstrahlten, finden wir die überkommene Systematik der Bassprogressionen.

Gleichzeitig verband sich das aus der Klausellehre hervorgegangene Paradigma der sequenziellen Verkettung von Kadenzmodulen (allzumal in der deutschen RameauRezeption) mit der tradierten kontrapunktischen Mechanik. So überrascht es nicht, dass in Deutschland mit Marpurg und Kirnberger gerade jene Autoren, die sich als Theoretiker am deutlichsten die Gedanken Rameaus zu eigen machten, in ihren Generalbassschulen ${ }^{57}$ und in der praktischen Kompositionslehre ${ }^{58}$ die Tradition sequenzieller Satzmodelle fortschrieben. In der am Paradigma des sequenziellen Stufenganges ausgerichteten Fundamentschritttheorie der Wiener Schule (Sechter) schließlich gerieten die alten Modelle im 19. Jahrhundert gänzlich in eine Gemengelage aus tradiertem Kontrapunkt, harmonisch-grundtonbezogenem Denken, schematisierten Terzentürmen und problematischen Tonalitätsbegründungen: Ein Grund mehr für einen Gang sad fontes`.

\section{Modelle}

Nach diesem historischen Abriss sollen nun die Satzmodelle selbst im Vordergrund stehen. Dabei schöpfen wir vor allem aus zwei zentralen Quellen, die für uns sowohl von ihrer Entstehungszeit her als auch inhaltlich von besonderem Interesse sind: Lusitanos Introduttione von 1553 (adaptiert durch Picerli 1630) und Cerretos Prattica musica von 1601 (adaptiert durch Zacconi 1622). ${ }^{59}$

\section{Gegenschrittmodelle}

Die Quellen des 15. und 16. Jahrhunderts demonstrierten die kanonische Führung von Gegenschritten ausgehend von zweistimmigen Satzgerüsten (vgl. Beispiele 2 und 3, S. 16). Zur Drei- oder Mehrstimmigkeit führten mehrere Wege: Improvisatorisch am einfachsten umzusetzen war die Führung der Oberstimme in Dezimenmixturen zur tiefsten Stimme. ${ }^{60}$ Ebenfalls möglich war die Kombination mehrerer Kanonmodelle: Für QuartTerz-Gegenschritte und Quintschritte stehen jeweils alternative Konstellationen im Terzabstand zur Verfügung (Beispiel 9a: Oktavkanon, Beispiel 9b: Unterquintkanon), die sich problemlos miteinander verbinden lassen. Dezimenmixturen zum Cantus firmus können den Satz zur Vierstimmigkeit ergänzen.

57 Johann Philipp Kirnberger, Grundsätze des Generalbasses (1781-1782) und Friedrich Wilhelm Marpurg, Handbuch bey dem Generalbasse und der Composition (1755-1760).

58 Marpurg, Abhandlung von der Fuge (1753/54).

59 Die Notenbeispiele folgen den Partiturumschriften Zacconis und Picerlis.

60 Der Dezimensatz des Diskants (bezogen auf den Tenor bzw. die tiefste Stimme des Satzes) gehörte zu den grundlegenden Techniken des Contrapunto alla mente (vgl. Guilielmus 1965, Kap. 6, 42 sowie Sachs 1984, 175 f.). 


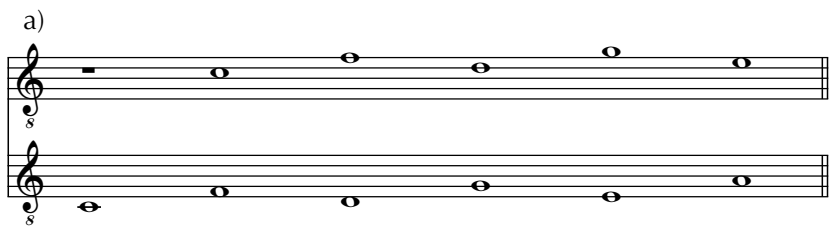

b)

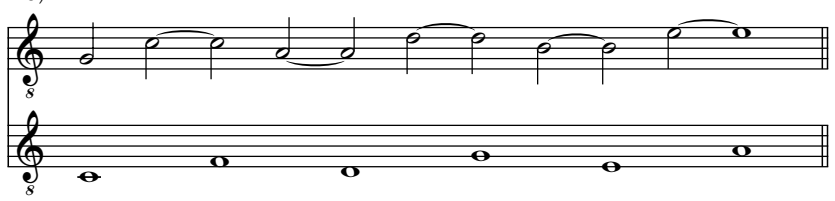

Beispiel 9: Hothby 1977, 88 ff.: a) Ex. 10, b) Ex. 11

Wurde im Contrapunto alla mente die Kanonbildung nicht direkt auf den Cantus firmus bezogen, so definierte ein Konsonanzenschema das Verhältnis der jeweils führenden Kanonstimme zum Cantus firmus. Für den »Canto fermo per quarte in voce basse« weist Lusitano auch solche Intervallprogressionen an, die bereits für sich gesehen eine Kanonstimme zum Cantus firmus ausbilden, nun aber ihrerseits sekundäre Kanons initiieren können. Aus der Gegenbewegung von der Dezime in die Quinte ${ }^{61}$ etwa resultiert ein Kanon in der Quarte (bzw. Unterquinte), der im Verhältnis zum Cantus firmus auf den bereits erwähnten Dezimensatz hinausläuft (Beispiel 10a; 10b zeigt das entsprechende Verfahren für den Terz-Sekund-Gegenschritt).

a)

b)

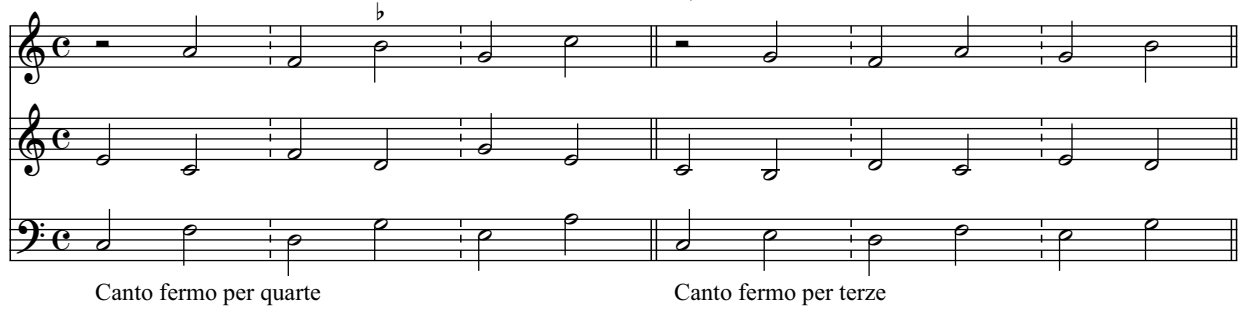

Beispiel 10: nach Lusitano 1553: a) »fuga in diatesaron«, 19b, Abs. 4; b) »fuga si fa in diapente«, 19a, Abs. 1

Imitatorische Sequenzen auf der Grundlage von Gegenschrittkanons finden sich in zahlreichen Kompositionen um 1500, etwa in Josquin des Prez' Trauermusik für Ockeghem (Beispiel 11, S. 29). ${ }^{62}$ Die sequenzielle Faktur ist rhetorisch motiviert durch die nament-

61 »La prima farà al salire [...] due decime, \& poi quinta, quinta [...]« (Lusitano 1553, 19b, Abs. 4). Das nach gleichem Muster fallende Modell wird von Lusitano nicht mitgeteilt.

62 Diese Faktur ist bei Josquin kein Einzelfall, vgl. etwa die Motette Gaude Virgo, Mater Christi, T. 67-72. 
liche Aufzählung einer ganzen trauernden Komponistengeneration. Der Satz spiegelt einen weiteren gängigen Weg zur Vierstimmigkeit: Das zweistimmige Kanongerüst (Tenor und Bass im Unterquintkanon) lässt sich durch die Führung des Soprans im Dezimensatz zur Dreistimmigkeit ergänzen; eine vierte Stimme kann sich nun ihrerseits auf die Dezimenmixtur beziehen (Sopran und Alt im Unterquintkanon). ${ }^{63}$

Tomás de Santa María präsentiert diese kontrapunktische Konstellation als instrumentales Improvisationsmodell, mithin als von vornherein vierstimmigen Komplex (Beispiel 12). Solche sModellkomplexe dürften einem erfahrenen Komponisten des 16. Jahrhunderts synchron zur Verfügung gestanden haben. Alle Stimmen des Satzes konnten so bereits im Kompositionsvorgang aufeinander bezogen sein, ohne dass zum Verständnis eine anachronistische Bezugnahme auf das 'Konzept des Akkords` erforderlich wäre. ${ }^{64}$ Strukturell beruhen Fakturen wie der Sequenzabschnitt aus Josquins Trauermusik auf der Anlagerung von Mixturen - eine Technik, die sich spätestens in der Generation Monteverdis als allgegenwärtiger satztechnischer Standard etablierte (Beispiel 13).

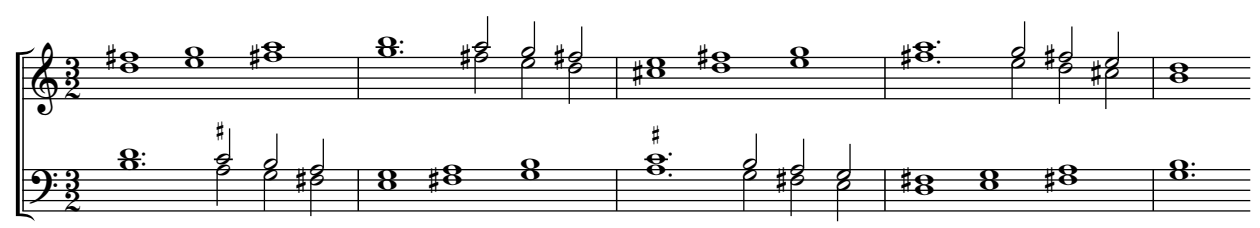

Beispiel 13: Claudio Monteverdi, Questi vaghi concenti (5. Madrigalbuch), Sinfonia prima, T. 13-17

Systematisch entfaltet wurde das Konzept der Mixturenanlagerung freilich erst in der Musiktheorie des 18. Jahrhunderts: ${ }^{65}$ Die jüngeren Quellen legen Denkweisen offen, die auf das 15. und 16. Jahrhundert zu beziehen weit weniger anachronistisch sein dürfte, als bloße Jahreszahlen es vermuten ließen. ${ }^{66}$

Synkopierte Kanonbildungen im Quintabstand lassen sich in der Regel als rhythmische Antizipationen (seltener Retardationen) interpretieren und strukturell auf einen Satz `Note gegen Note` zurückführen. So bilden in Beispiel 14 beide Oberstimmen jeweils einen Oberquintkanon zum Cantus firmus des Basses (»Seguito« in Beispiel 14a: synkopisch retardierend, "Guida« in Beispiel 14b: synkopisch antizipierend). Problemlos ließen sich die alternativen (metrisch zueinander verschobenen) Oberstimmensätze (Beispiele 14a und 14b) ıübereinander legen . Vom gemeinsamen Bassbezug der Ober-

63 Die Bildung einer Kanonstimme zur Dezimenmixtur wird von Lusitano, obgleich sehr naheliegend, nicht beschrieben.

64 Vgl. Helms 2001, 23, mit Bezug auf Dahlhaus 1968, 76.

65 Etwa bei Werckmeister 1702, 98, § 172. Für den gesamten Zusammenhang vgl. Froebe i. V.

66 Man denke etwa an smechanische` Praktiken der Stimmenverdoppelung im Sight-Singen des 15. Jahrhunderts (vgl. Sachs 1982, $171 \mathrm{ff}$.). Im Bereich der Organistenkunst konnten kontrapunktische Mixturenanlagerungen seit dem 15. Jahrhundert als scanones sine pausis` (Kanons ohne Einsatzabstand) verstanden werden, eine Bezeichnung, derer sich noch Samuel Scheidt in der Tabulatura nova bediente (vgl. Gurlitt 1966, insbes. 106f.). 


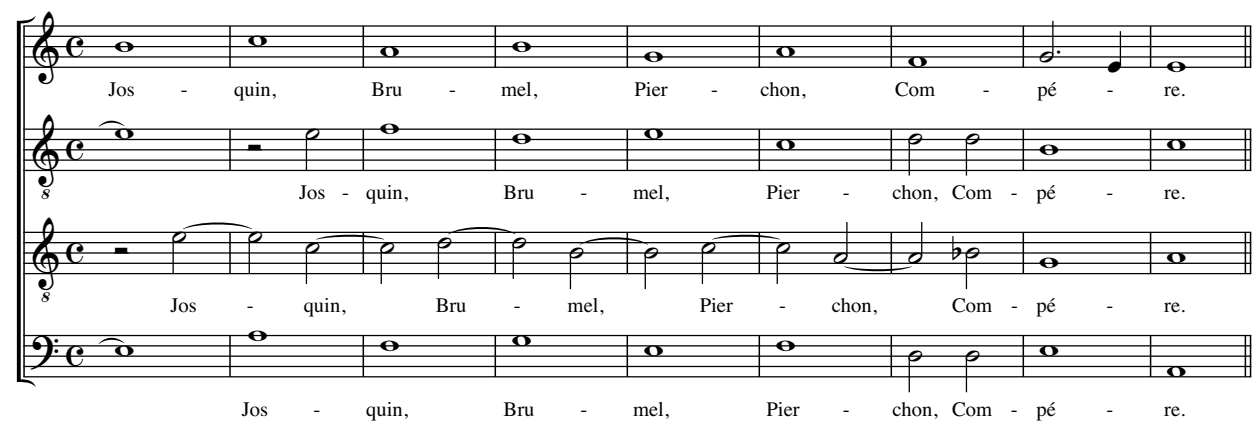

Beispiel 11: Josquin des Prez, La déploration sur la mort de Johannes Ockeghem, T. 118-126

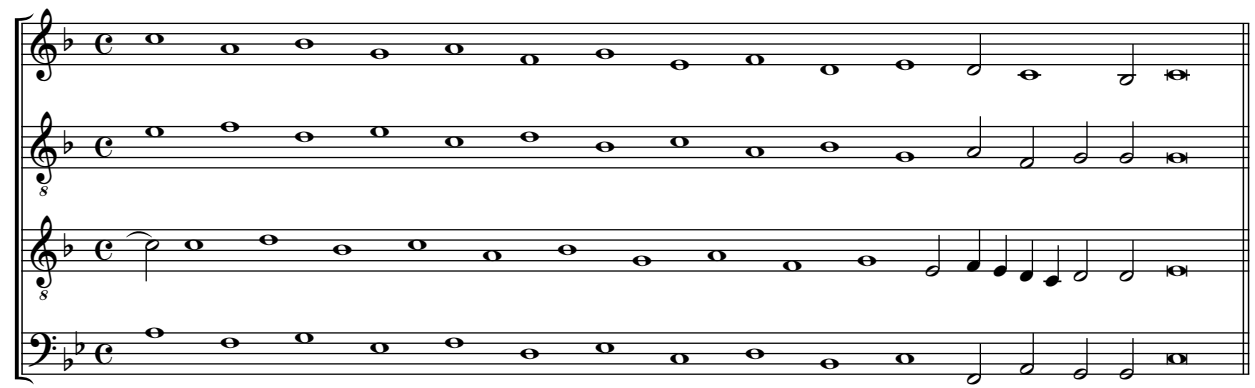

Beispiel 12: Santa María 1565, II, Kap. 18, 49

a)

b)

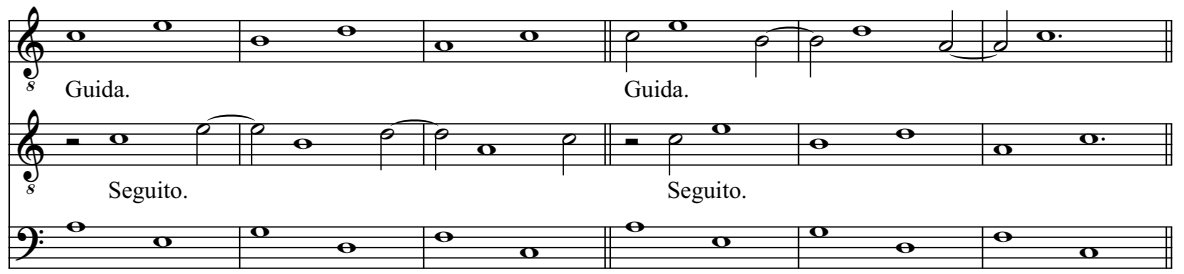

c)

d)

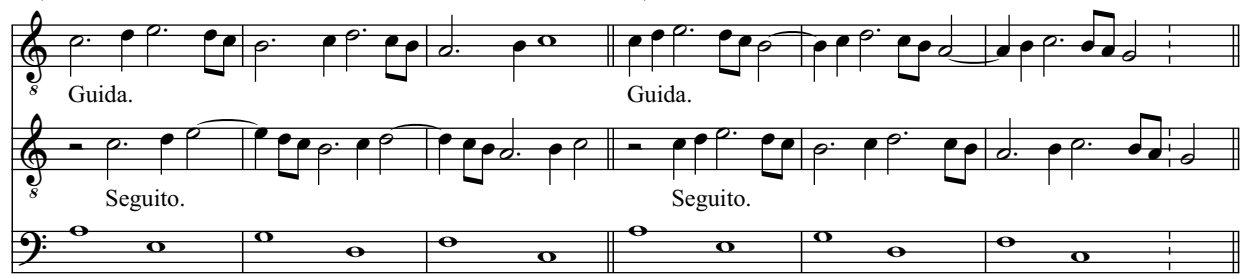

Beispiel 14: Zacconi 1622, 189 (= Cerreto 1601, 284), Ex. 6,1-4 (vgl. Lusitano 1553, 19a, »Canto fermo per quarte $[\ldots] \ll$, Abs. $2^{67}$ 
stimmen her gesehen erweist sich der von Cerreto instruierte Synkopenkanon »all' unisono« als sakzidentiell: Er käme im Satz `Note gegen Note` einer Verdoppelung der Oberstimmen gleich.

Als sManier dienten synkopische Imitationen der rhythmischen Auflockerung des Contrapunctus simplex und ermöglichten im diminuierten Satz ein dichtes komplementärrhythmisches Ineinandergreifen der Figuren. Zugleich aber handelte es sich um ein elegantes Mittel der Stimmenvermehrung, insbesondere in mehrchörigen Kompositionen: Quart-Terz-Gegenschritte und Quintschritte lassen sich jeweils bis zur Sechsstimmigkeit fügen, wenn zum vierstimmigen Mixturensatz Note gegen Note noch synkopisch verschobene Einsätze hinzutreten. ${ }^{68}$ Als Modellkomplexe stellen diese Maximalformulierungen zugleich einen großen Vorrat kontrapunktischer Konstellationen bereit (Beispiel 15). ${ }^{69}$

Die Sechsstimmigkeit des prachtvollen »Gloria Patri« aus dem Magnificat a 6 (das in Monteverdis Sammlung von 1610 wohl als mögliche Alternative sda cappella zum Magnificat der Marienvesper vorgesehen war) ist nach diesem Prinzip geschaffen (Beispiel 16).

\section{Fauxbourdonvarianten}

Bereits Hothby kannte die konsonanten Synkopationen 5-6 (steigend) und 6-5 (fallend) als Imitationsmodelle ${ }^{70}$, und Aaron stellt fest, eine solche »fuga« werde »sym[n]copata" genannt und komme nicht allein im Niedersteigen vor, sondern auch im Aufsteigen. ${ }^{71}$ Zweifellos gehört die steigende 5-6-Consecutive zu den zentralen Modellen noch des 17. und 18. Jahrhunderts. Vicentinos Urteil über den »modo di fugare per sesta \& quinta«, er sei unmodern und ungebräuchlich, kann allenfalls für das fallende Modell Gültigkeit beanspruchen ${ }^{72}$, das bis Mitte des 17. Jahrhunderts weitgehend durch den (der Klauselsynkope verwandten) Septimenvorhalt abgelöst wurde. (Septimen- bzw. Sekund-

67 Diese um 1622 (dem Erscheinungsjahr von Zacconis Prattica di musica) ausgesprochen zeittypische Faktur findet sich in einer Beispiel 14d entsprechenden Gestalt bereits in Josquins Praeter rerum seriem a 6 (T. 26-29), eingebettet in den Kontext einer sechsstimmigen Cantus-firmus-Bearbeitung.

68 Quart-Terz-Gegenschritte erlauben unter Einbeziehung von Sexten über dem Bass sogar eine siebenstimmige Kanonführung (fallend: retardierende Synkopation der Terzmixtur zum Bass, steigend: antizipierende Synkopation); weitere Konstellationen sind im geringerstimmigen Satz möglich (vgl. Beispiel 14). Einzig für Kanonbildungen aus Terz-Sekund-Gegenschritten ist der Satz strukturell auf Vierstimmigkeit begrenzt, da sich Sekundschritte aus der Prim oder Oktav nicht in dichter Imitation (per arsin et thesin) führen lassen.

69 Die bei schematischer Durchführung unvermeidlichen Tritoni bedürfen der Korrektur, sei es durch Akzidentiensetzung, Diminution oder melodische Veränderungen. In den Worten Werckmeisters: »Diese Fugen kön[n]ten noch auff unterschiedliche Arth [...] eingerichtet werden [...], so werden auch die gar zu blossen Consonantien und Tritoni [...] verbessert: [...]«(1702, 118, § 193).

70 Hothby 1977, 90f., Ex. 11.

71 „Verum ut noris: cur in tali compositione fuga dicatur symcopata: quae non solum in descensu fit, sed etiam in ascensu: [...]« (Aaron 1516, III, Kap. 52; vgl. auch Apfel 1981, 152). Noch Berardi

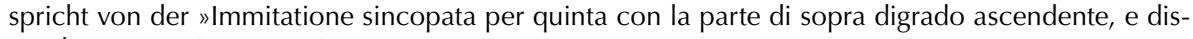
cendente $[\ldots] \ll(1689,130)$.

72 Vicentino 1555, IV, Kap. 23, 80. 
Quart-Terz-Gegenschritt

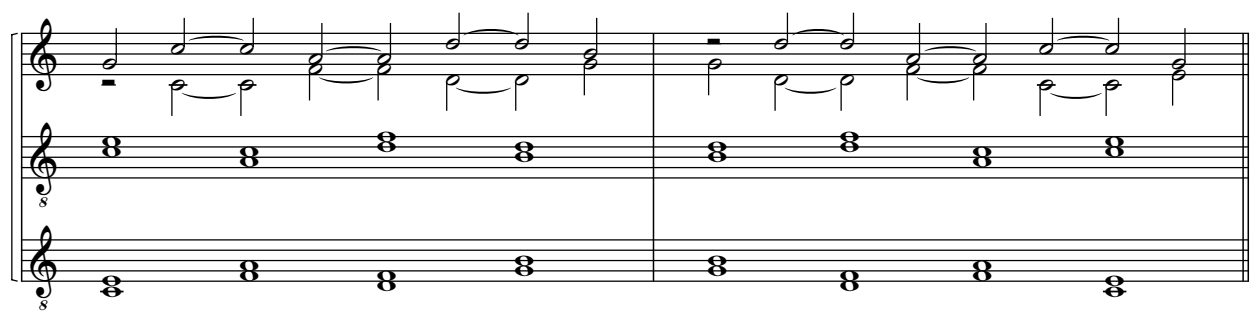

Terz-Sekund-Gegenschritt

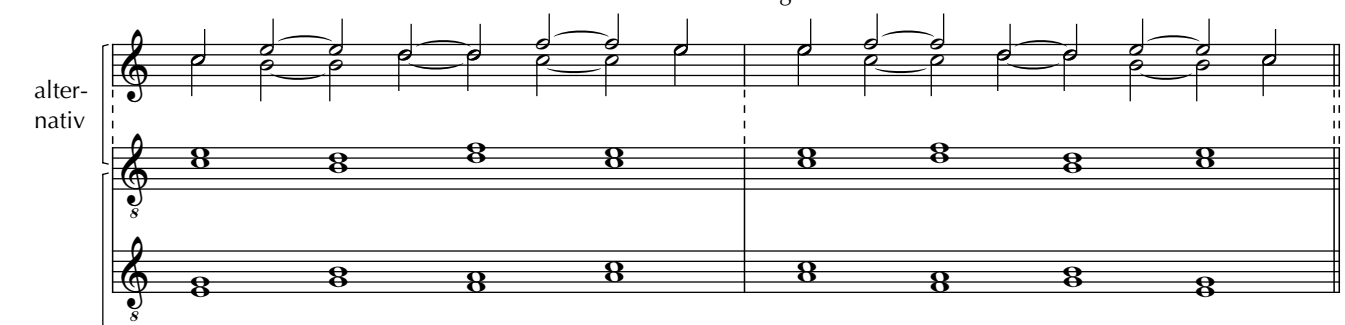

frei

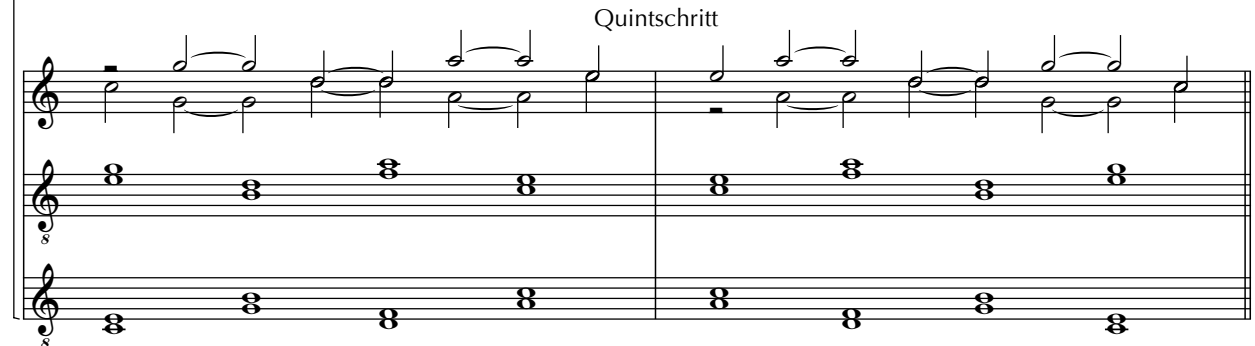

Beispiel 15: Modellkomplexe

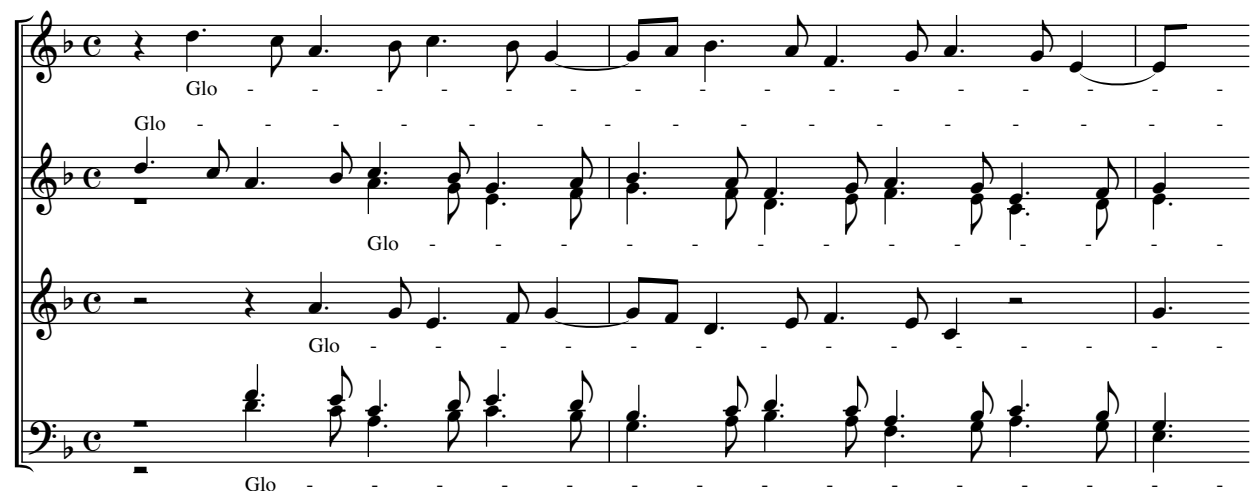

Beispiel 16: Claudio Monteverdi, Magnificat a 6 voci (1610), Gloria Patri, T. $1 \mathrm{ff}$. 
vorhaltsketten spielen in den Quellen des 16. Jahrhunderts eine untergeordnete Rolle, obwohl bereits Guilielmus sie als Regelfall der fallenden Synkopenkette beschreibt. $)^{73}$ Verwandt mit diesen fauxbourdonartigen Fakturen sind verschiedene Modelle, die den Sekundgang des Basses durch Gegenschrittkanons der Oberstimmen kontrapunktieren. Die wohl älteste Form beruht auf einem Oktavkanon aus Quart-Terz-Gegenschritten und ist durch Akzentparallelen der führenden Kanonstimme in der Intervallfolge 8-6 (steigend) bzw. 8-5 (fallend) gekennzeichnet.

a) b)

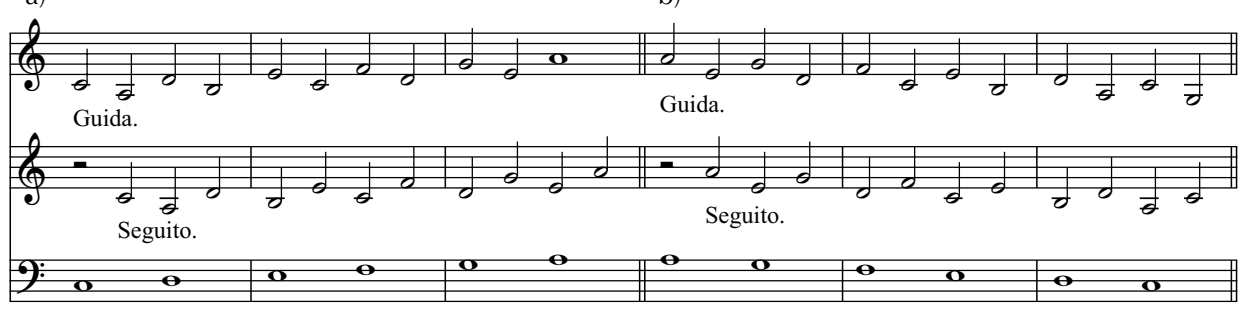

Beispiel 17: Zacconi 1622, 186 f. (=Cerreto 1601, 282): a) Ex. 1,1; b) Ex. 2,1 (vgl. Lusitano 1553, $17 \mathrm{a}$, »Canto fermo gradatim [...], Abs. 2; Vicentino 1555, 80; Tigrini 1588, 118)

Wiederum weiß Vicentino zu berichten, das Modell werde nur noch von »einigen NichtModernen « (»alcuni non moderni«) gebraucht ${ }^{74}$, und auch Tigrini betont, solche Fugen seien »nicht sehr angenehm« zu hören. ${ }^{75}$ Gleichwohl wird noch Muffat rund 150 Jahre später Oberstimmensätze, die auf Akzentparallelen vollkommener Konsonanzen beruhen (5-8 und 8-5), als Regelfall präsentieren. Es scheint, als hätten diese Modelle die letzten Jahrzehnte des 16. Jahrhunderts in der Instrumentalmusik gewissermaßen ıüberwinterts, um in diminuierter und sausgeterzter Form mit dem frühen 17. Jahrhundert wieder zum satztechnischen Standardrepertoire zu gehören.

Moderner und im geringstimmigen Satz seleganter ist eine von Parallelen unvollkommener Konsonanzen ausgehende Faktur (steigend 3-6, fallend 3-5 bzw. 6-3). ${ }^{76}$ Bereits Lusitano beschreibt die Möglichkeit, das Modell durch einen synkopierenden Einsatz zur Vierstimmigkeit auszubauen (Beispiel 18). ${ }^{77}$

Beide Kanonmodelle kennzeichnet das regelmäßige Alternieren zwischen Quinten und Sexten im Oberstimmensatz, ein Strukturzusammenhang, der im Generalbasssatz

73 Guilielmus 1965, Kap. 8, »Regula circa cognitionem syncoparum«, 53 (vgl. Riemann 1929, 300f.). Der kompositionspraktische Ort dissonanter Synkopenketten bleibt zunächst die `Rückstrahlung` der finalen Klauselsynkope ins Klauselvorfeld.

74 Vicentino 1555, IV, Kap. 23, 80.

75 »Le quali fughe non sono però grate all'udito« (Tigrini 1588, IV, Kap. 12, 118). Cerreto hingegen stellt fest, das Modell eigne sich »sehr gut« als Gerüst für die mehrchörige Komposition (1601, IV, Kap. 3, 270).

76 Noch Werckmeister bringt den steigenden Gerüstsatz ohne synkopierenden Einsatz und »in stylo Simplici« als »Exempel« für einen Kanon »auff ein gewisses Subjectum« (1702, 116, § 192). Im Anschluss überträgt er das Konsonanzenschema 3-6 modernisierend auch auf den fallenden Sekundgang.

77 Lusitano 1553, 17a, »Canto fermo gradatim«, Abs. 1. 


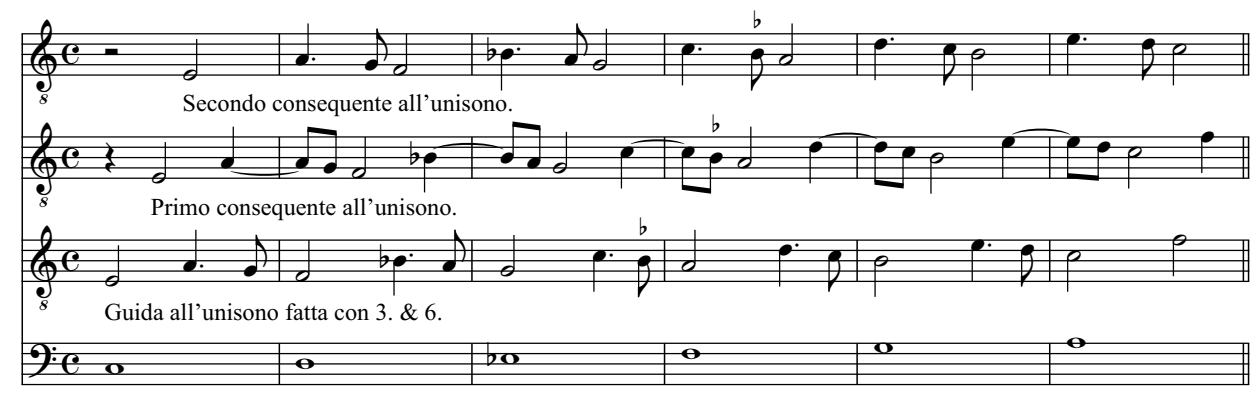

Sogetto ascendente per seconde.

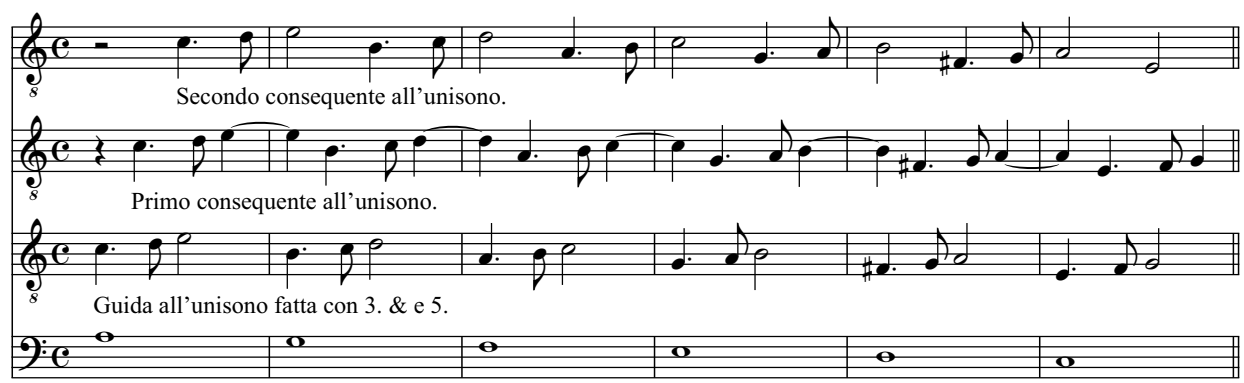

Sogetto discendente per seconde.

Beispiel 18: Picerli 1630, 101 (vgl. Lusitano 1553, 17a, »Canto fermo gradatim [...], Abs. 1;

Tigrini 1588, 118)

a) Schöne Abwexlung der Quinten und Sexten
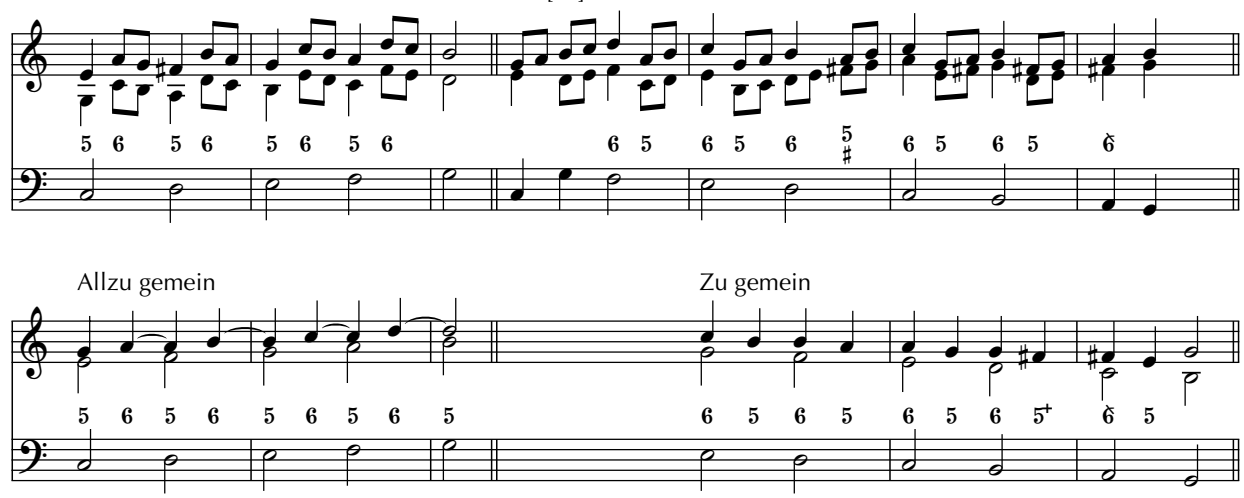

Beispiel 19: Muffat 1699, a) 84 f., b) $87 f$., Beispiele gekürzt 
des 17. Jahrhunderts offenkundig wird. So hält Muffat den durch die Bezifferungen 5-6 und 6-5 implizierten Synkopensatz für »allzu gemein« und offeriert stattdessen die figurative Ausgestaltung der Oberstimmen durch Quart-Terz-Gegenschritte (Beispiel 19, S. 33). ${ }^{78}$ Die Signaturenfolge des Generalbasses bewahrt die ältere Satzschicht und bindet die Sprungmelodik des Oberstimmensatzes an das lineare Synkopenmodell. ${ }^{79}$

Im folgenden Abschnitt aus Monteverdis Laudate pueri schält sich aus der latenten Fauxbourdon-Faktur eine Einsatzfolge aus Quart-Terz-Gegenschritten heraus, wobei die Einsätze (mit den alternierenden Intervallfolgen 5-8 und 3-6) einander jeweils als Terzmixturen anlagern.

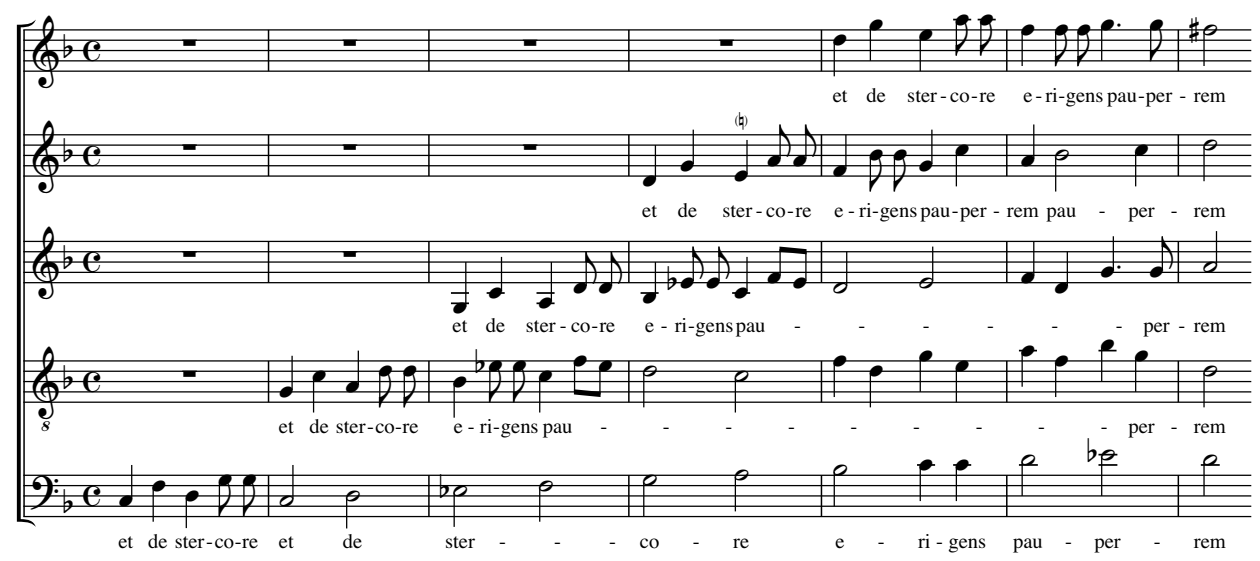

Beispiel 20: Claudio Monteverdi, Laudate pueri a 5 voci da Cappella (Missa et psalmi), T. 78-84

\section{Diminution: Quintbrechung und Terzenketten}

Lusitano unterschied zwischen der kanonischen Führung des Cantus firmus mit sich selbst (»fugare il canto«) und Kanons, die ihrerseits einen Cantus firmus kontrapunktieren (»Fughe sopra il canto«). Für Letztere lässt sich aus den Beispielen Cerretos eine Systematik herauslesen, die auf der sukzessiven Zunahme von Diminutionsgeschwindigkeit und Ambitus beruht: Auf einfache Gegenschrittkanons folgen Kanons auf Grundlage von steigenden oder fallenden Quinttiraten (bzw. gebrochenen Quintschritten), während in einer weiteren Gruppe Septimentiraten (bzw. Terzenketten) den übergeordneten Sekundgang vermitteln oder strukturelle Quintschritte diminutiv weiten. Folgende Gerüste liegen den diminuierten Kanonbildungen bei Lusitano (bzw. Picerli) und Cerreto (bzw. Zacconi) zugrunde:

78 Die Gegenschritte der Oberstimme (Intervallfolge 3-6 bzw. 6-3) wechseln sprungweise zwischen Dezimenmixtur und Synkopenstimme und sind im Griffmuster des synkopierten Oberstimmensatzes latent.

79 Federhofer spricht sinngemäß von einem »Netz der realen oder latenten Stimmbahnen, die mit der Generalbaßakkordik vorgegeben sind« $(1981,161)$. 

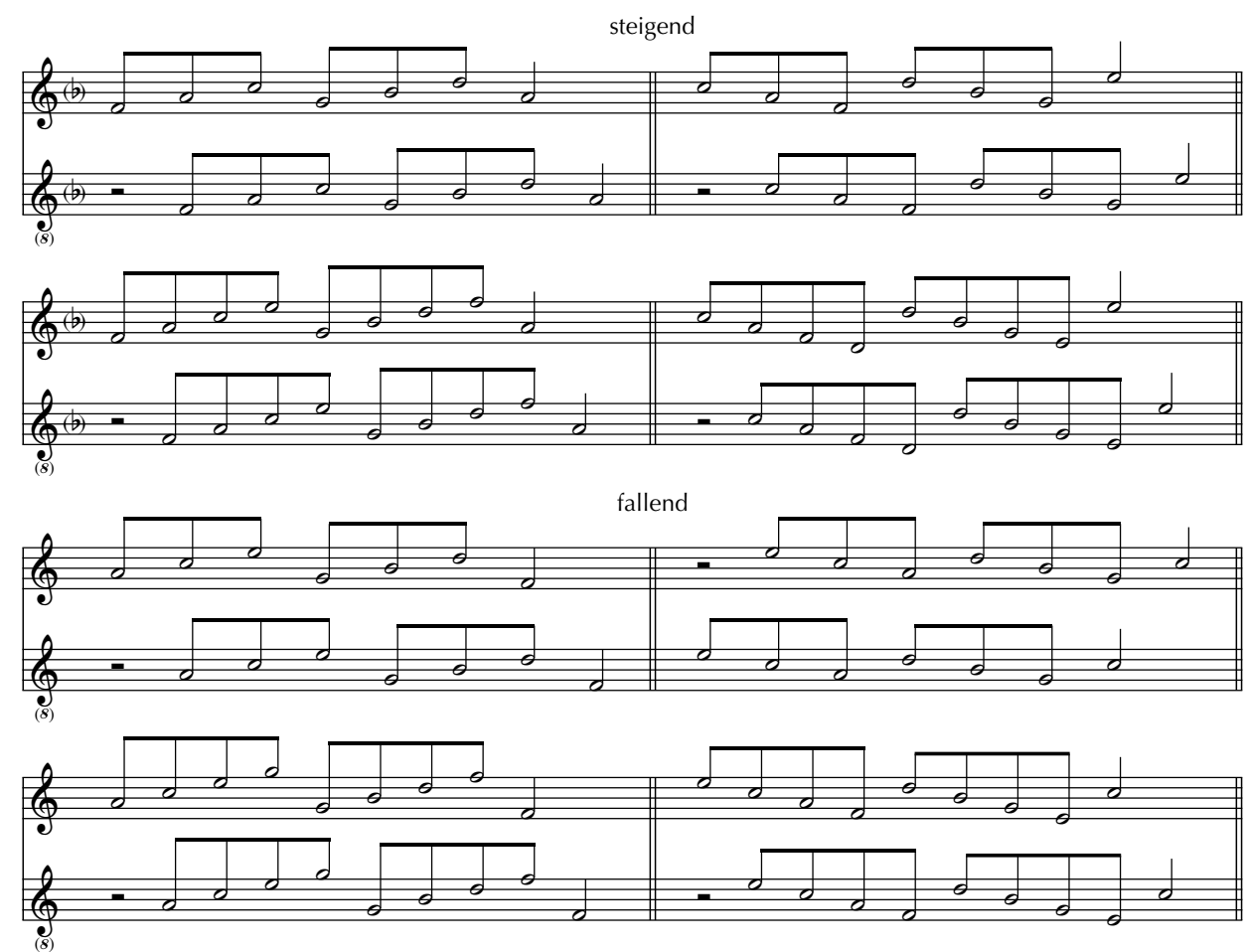

Beispiel 21: Kanonmodelle aus gebrochenen Quintschritten und Terzenketten

Gebrochene Quintschritte

Cerretos Kanons (deren Konsonanzenschemata teilweise schon Lusitano bringt) zeigen die Quintbrechung ${ }^{80}$ auch im Gerüstsatz (Beispiele 22c und 22d, S. 36); Reduktionen auf einen Satz `Note gegen Note offenbaren einen Satzhintergrund aus einfachen Gegenschrittmodellen.

a)

b)

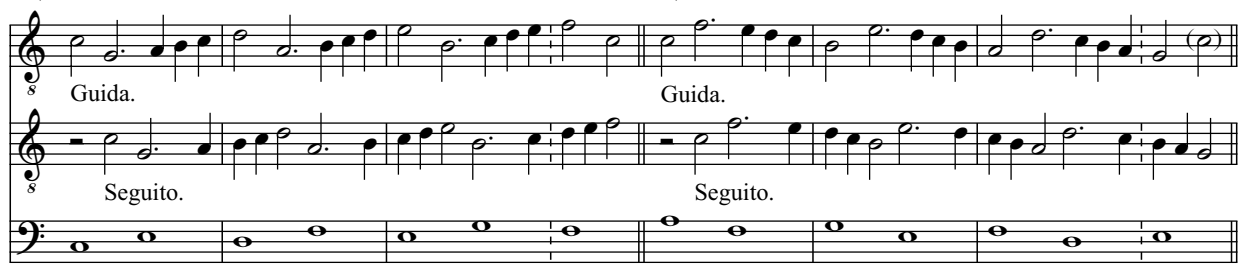

Beispiel 22: Zacconi 1622, 187f./190 (=Cerreto 1601, 283/285): a) Ex. 3,1; b) Ex. 4,1

80 Der Terminus ist nicht streng im Sinne Schenkers zu verstehen: Ein sgebrochener Quintfall kann sich in der kontrapunktischen Reduktion als diminutive Weitung der fallenden Terz erweisen. 
C)

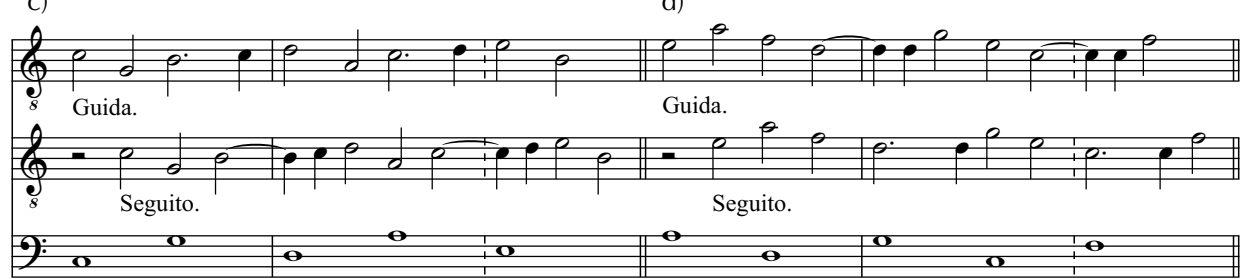

e)

f)

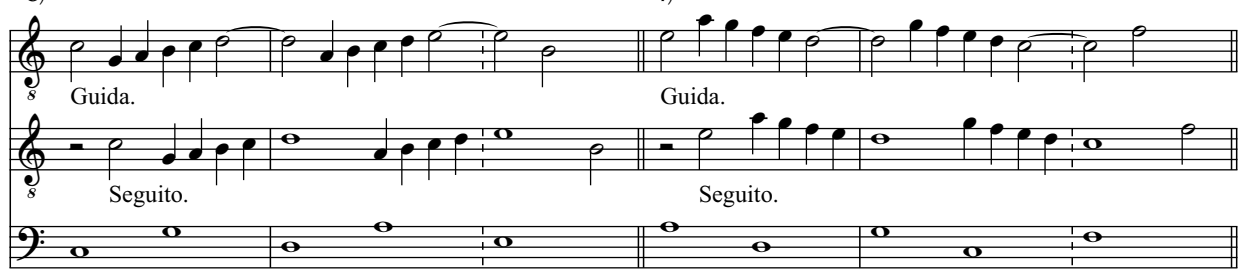

Beispiel 22 (Fortsetzung): Zacconi 1622, $187 \mathrm{f} . / 190$ (=Cerreto 1601, 283/285):

c) Ex. 7,1; d) Ex. 8,2; e) Ex. 7,3; f) Ex. 8,1 (vgl. Lusitano 1553, 18a, „Canto fermo per terze«, Abs. 1)

Darüber hinaus integriert Cerreto die fallende Quintbrechung in die steigende Stufensequenz $^{81}$ (Beispiel 23b) und demonstriert nebenbei die Möglichkeit, den Oberstimmensatz auf die >Mixturebene` zu versetzen (Beispiel 23d). ${ }^{82}$

Alle auf Quintbrechung oder Terzenketten beruhenden Oberstimmenkanons sind potentiell doppelte Kontrapunkte in der Quinte (bzw. Duodezime). Zu den zweistimmigen Kanons kann (sofern der unterlegte Cantus firmus entfällt) jeweils ein dritter (oder gegebenenfalls sogar ein vierter) Kanoneinsatz auf der Oberquinte (`Quintstieg`) bzw. auf der Unterquinte (`Quintfallı) hinzutreten. Dreistimmige Kanonmodelle nach diesem Muster finden sich bereits in den zeitgenössischen Quellen. So fügte Zarlino seinem Kapitel zu den "Contrapunti à Tre voci, che si fanno à mente", das in der Hauptsache von der Cantus-firmus-Bearbeitung handelt, einen Abschnitt zu den »Consequenze, che si fanno di fantasia« bei. Aus den zwei sfreien Kanons, die Zarlino mitteilt, lassen sich charakteristische Modelle extrahieren, unter anderem der folgende Quintstieg-Kanon (Beispiel 24). ${ }^{83}$

81 Die umgekehrte Kombination - also die Integration der steigenden Quintbrechung in die fallende Stufensequenz - ist in den Quellen ohne Beispiel.

82 In Zacconis Adaption kommentiert: »[...] il medemo Canone [...] ma una Terza più alto« (1622, 189). In der Synopse ist sinngemäß der Bass eine Terz tiefer gesetzt (Beispiel 22d).

83 Zarlino 1573, III, Kap. 63, »[...] Contrapunti à Tre voci, che si fanno à mente in Consequenza sopra un Soggetto; \& d'alcune Consequenze, che si fanno di fantasia«. Beide Kanons übernimmt Sweelinck unverändert in seine Composition Regeln (1901, 78f.). 


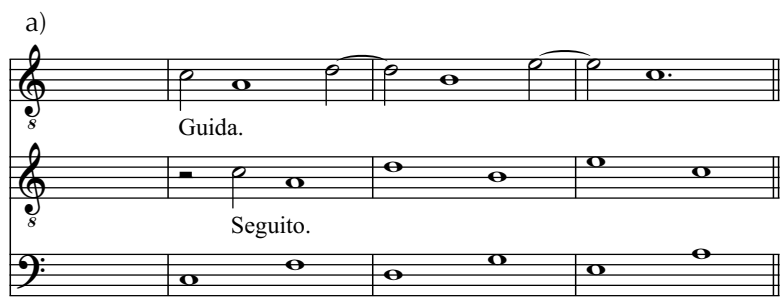

b)

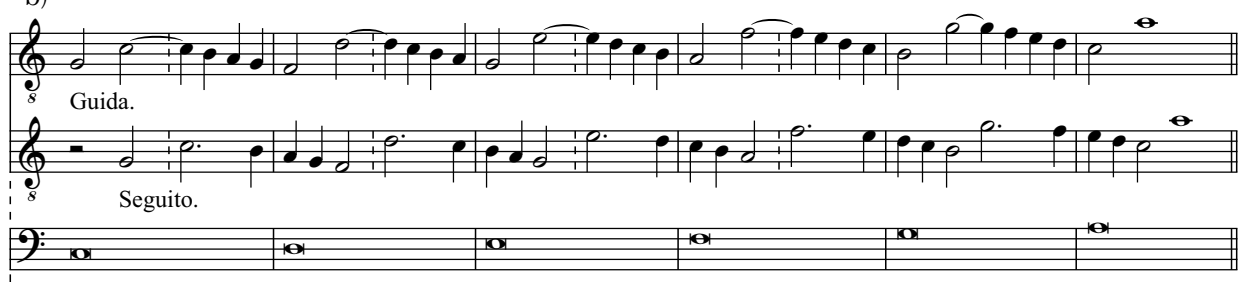

c)

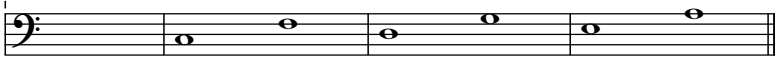

d)

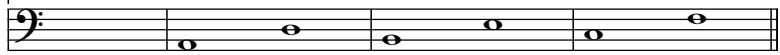

Beispiel 23: Synopse nach Zacconi 1622, 186/188f. (= Cerreto 1601, 281/284):

a) Ex. 5,1; b) Ex. 1,3 (original in halben Notenwerten); c) Ex. 5,2; d) Ex. 5, (original: c.f. und Oberstimmen eine Terz höher)

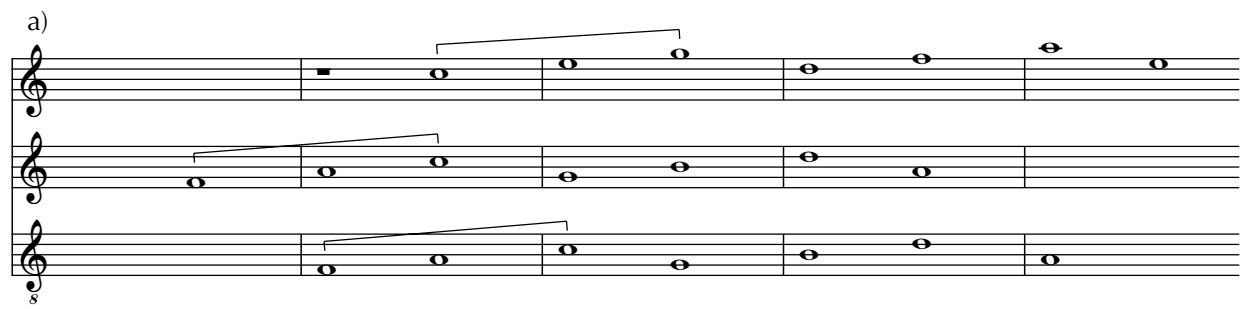

b)

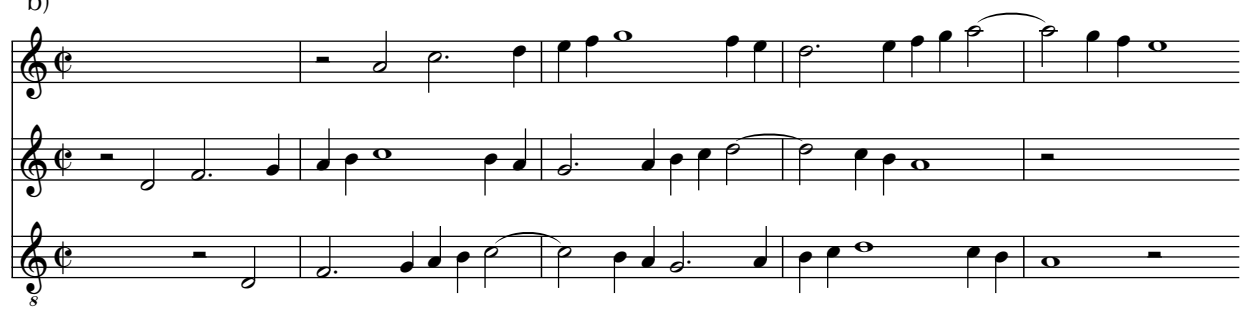

Beispiel 24: a) Quintstieg-Kanon (Gerüstsatz), b) Zarlino 1589, Kap. 63, 330, „Consequenza alla Diapason grave, \& alla Diapente acuta $[\ldots]$ «, T. 8-12 
Werden die Folgeeinsätze in Zarlinos Modell jeweils synkopisch antizipiert, so entsteht eine fünfstimmige Faktur, deren Einsatz in Monteverdis bis dahin solistisch konzertierendem $A$ Dio, Florida bella eine ungeheure Ausdrucksgewalt entfaltet. ${ }^{84}$
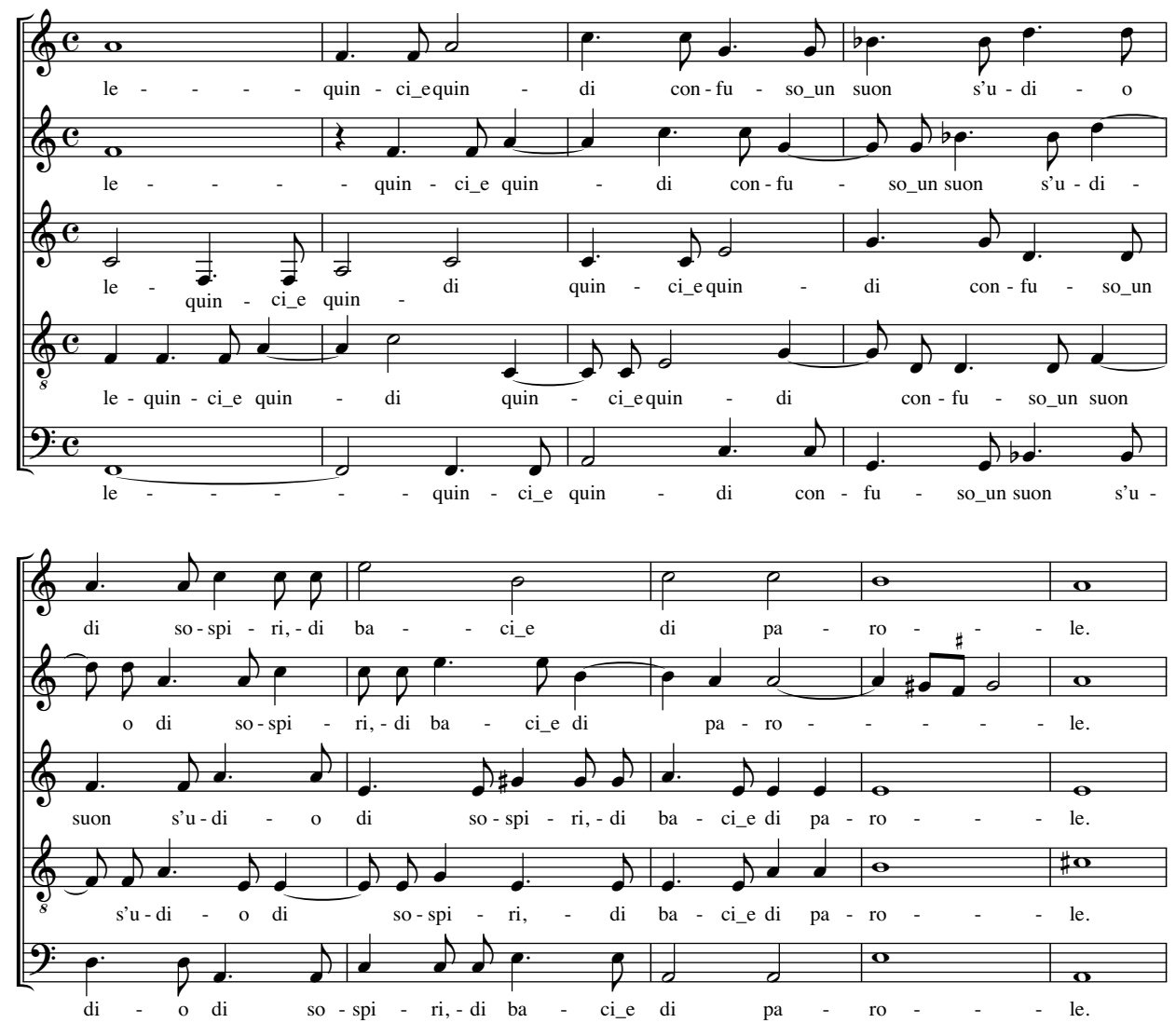

Beispiel 25: Claudio Monteverdi, A Dio, Florida bella, il cor piagato (6. Madrigalbuch), T. 42-50

Gallus Dressler nutzte 1563 das analoge Quintfallmodell als charakteristisches Beispiel für die Behandlung von Durchgangsdissonanzen. ${ }^{85}$

84 Eine Parallelstelle bei Josquin (Motette $O$ bone et dulcissime Jesu) exegetisiert de la Motte mit den Worten: »Der ganze Chor erhebt sich zum Herrn [...], und diese Erhebung geschieht mit satztechnischem Raffinement in unmerkbarer Klangverwandlung." (1981, 123) Das entsprechende 'Quintfallk-Modell verwendet Josquin in der Motette Absalon fili mi, (insbesondere T. 77-85). Der vierstimmige Doppelkanon in der Unterquinte wird von Fladt erläutert als »originäre[r] 'Fallk (auch semantisch) in die Tiefen des Quinten-Turms [...] (2005, 359).

85 »Exemplum de celeri transitu« (Dressler 1563, 223, Seitenzahlen nach Engelke). Die Übertragung des Notenbeispiels bei Engelke ist korrumpiert. 


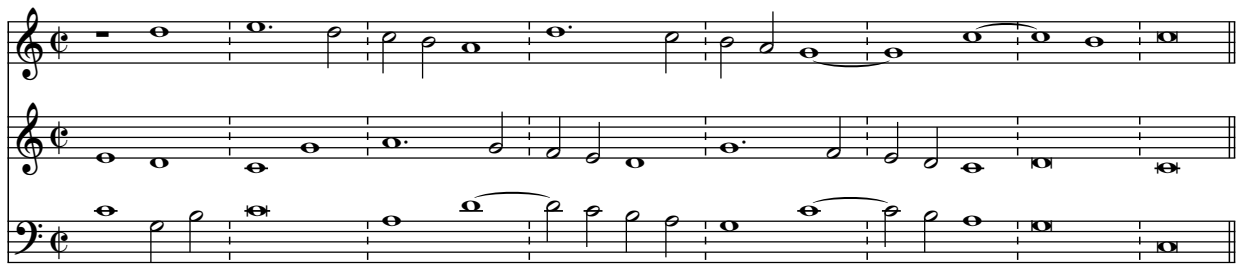

Beispiel 26: Dressler 1563, 223

In der charakteristischen Diminution als Quintskala mit punktierter Initiale handelt es sich Braun zufolge um ein Modell »aus der Sphäre des Gravitas-Ideals«, das »im letzten Jahrzehnt des 16. Jahrhunderts außerordentlich häufig« zu finden sei ${ }^{86}$, doch lässt sich die zugrunde liegende Imitationsformel (wenn auch meist nicht sequenziell fortgeführt) bis ins späte 15. Jahrhundert zurückverfolgen. Allein fünf Beispielsätze nach diesem Muster bei Herbst ${ }^{87}$ (jeweils mit dem aus der Punktierung ansetzenden Soggetto) spiegeln die anhaltende Beliebtheit des Modells, das in den Geistlichen Madrigalen und Evangelienmotetten der lutherischen Kirchenmusik bis etwa zur Jahrhundertmitte allgegenwärtig bleibt (Beispiel 27, S. 40). Eine Darstellung des Kanons »durch die Tertien« bietet noch Werckmeister in seiner »Zugabe [...] vom gedoppelten Contrapunct und fugis ligatis « ${ }^{88}$

Als Schlüsselsignal für die weihevolle Sphäre des sstile antico ‘ wirkte das (somit zum Topos gewordene) Modell in dieser Gestalt lange nach. Im Schlusschor (»Amen«) des Messiah führt Händel es (fallend wie steigend) in eine späte, große Apotheose (T. 42 ff.). Händels spätbarocke Beschwörung des sstile antico erweist sich als Destillat: In wohl kaum einer Komposition des 16. oder frühen 17. Jahrhunderts ist dieses zentrale Modell in solcher Reinkultur dargestellt worden. Nachfahren findet die Faktur in hochbarocken Formen der Quintfallsequenz, die sich aus fortlaufenden Tiraten in Terzenbzw. Dezimenkoppeln gewissermaßen herausschälen (vgl. Beispiel 27c).

86 Braun 1982, 58.

87 Drei Beispielsätze (ein `Quintstieg` und zwei `Quintfälle`) exemplifizieren bei Herbst die Behandlung von Punktierungen (1643, 21f.); zwei weitere Beispiele (jeweils ein `Quintstieg` und ein `Quintfallı) beziehen sich auf die (wie es scheint von Dressler abhängigen) Erläuterungen zur Durchgangsdissonanz (29). Herbst verweist ausdrücklich auf den konsonanten Gerüstsatz: »[...] im niderlassen [des Takts] aber muß man die besten consonantien gebrauchen / darauff die harmonia gleichsam fussen / und ans fundament sich halten [...] kan [...].»

88 Werckmeister 1702, 99, § 173. Marpurg (1754, Tab. XXXVII) zitiert einen entsprechenden Doppelkanon Gottfried Heinrich Stölzels. 
a)

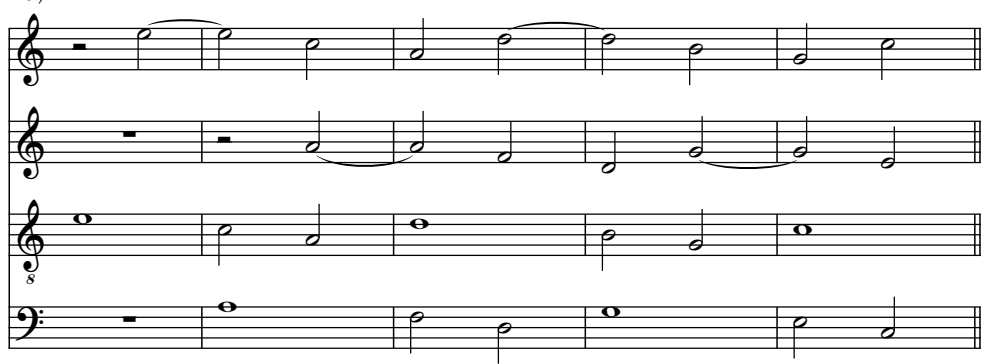

b)

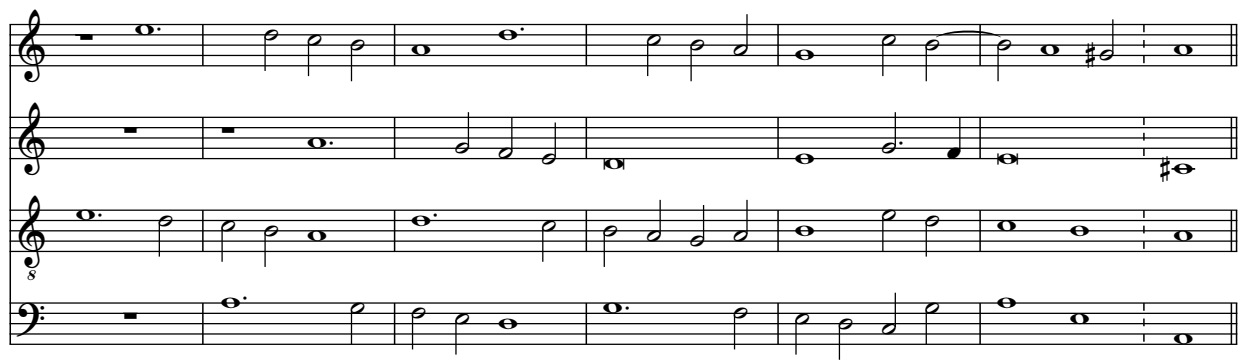

C)

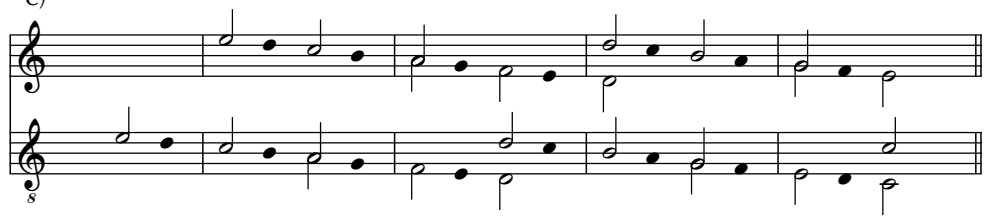

Beispiel 27: a) Quintfall-Doppelkanon (Gerüstsatz); b) Herbst 1643, 29;

c) Folie: Terzenketten im Dezimensatz

Terzenketten und konzertierende Tiraten

Eine elementare Improvisationstechnik des passagierenden Kontrapunkts erläutert Lusitano unmittelbar vor der »aria de cantar il contrapunto «: ${ }^{89}$ Der Kontrapunkt besteht dabei aus einer Skalenfigur, die das Komplementärintervall zur Progression des Cantus firmus füllt. In Lusitanos Beispielen wird jeweils der Sekundschritt des Cantus firmus durch eine Septimentirata in Gegenbewegung kontrapunktiert. ${ }^{90}$

89 Lusitano 1553, 14b (vgl. Tigrini 1588, 119).

90 Eigentümlicherweise thematisiert Lusitano ausschließlich Gegenbewegung aus der Prim in die Oktave (und umgekehrt), obwohl es naheliegend wäre, das Verfahren auf die unvollkommenen Konsonanzen zu übertragen. 


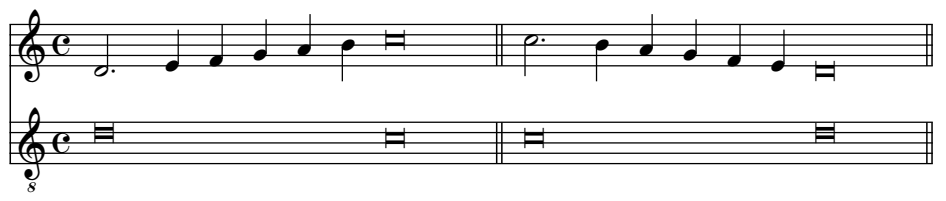

Beispiel 28: Lusitano 1553, 14b

Lusitanos passagierender Kontrapunkt lässt an instrumentale Diminutionsformeln der Tastenmusik um 1600 denken: Im fallenden `Fauxbourdon « verdoppelt der Diskant meist nach Lusitanos Muster die Bassprogression in skalarer Gegenbewegung (Beispiel 29, T. 2 f.), während im steigenden `Fauxbourdon` regelmäßig die Dezimenmixtur diminuiert wird (T. 1).
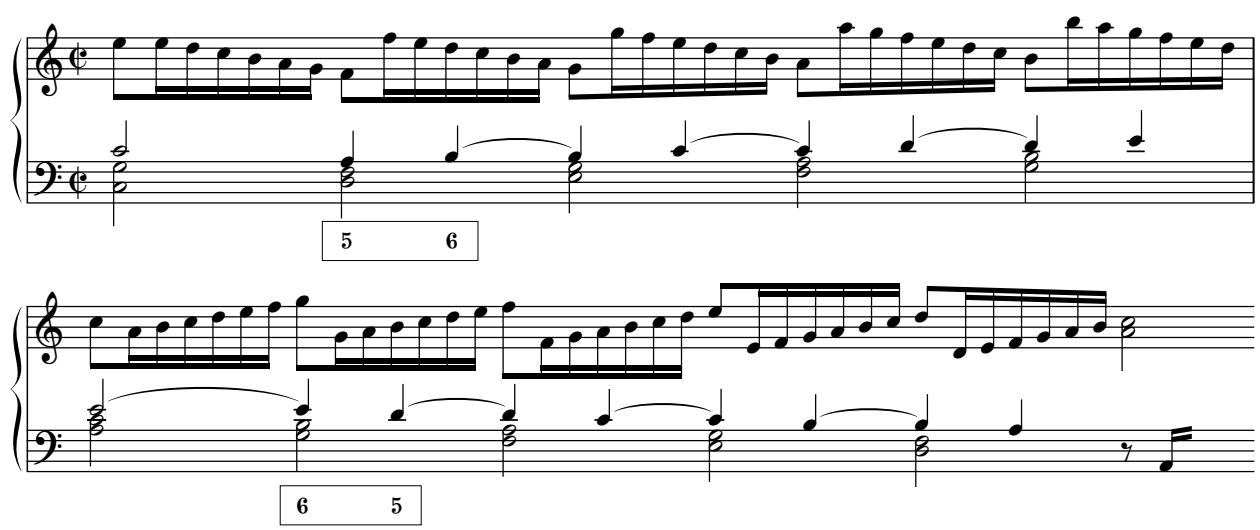

Beispiel 29: Girolamo Diruta, I/ Transilvano (1593), 28, »Toccata di Paolo Quagliati«
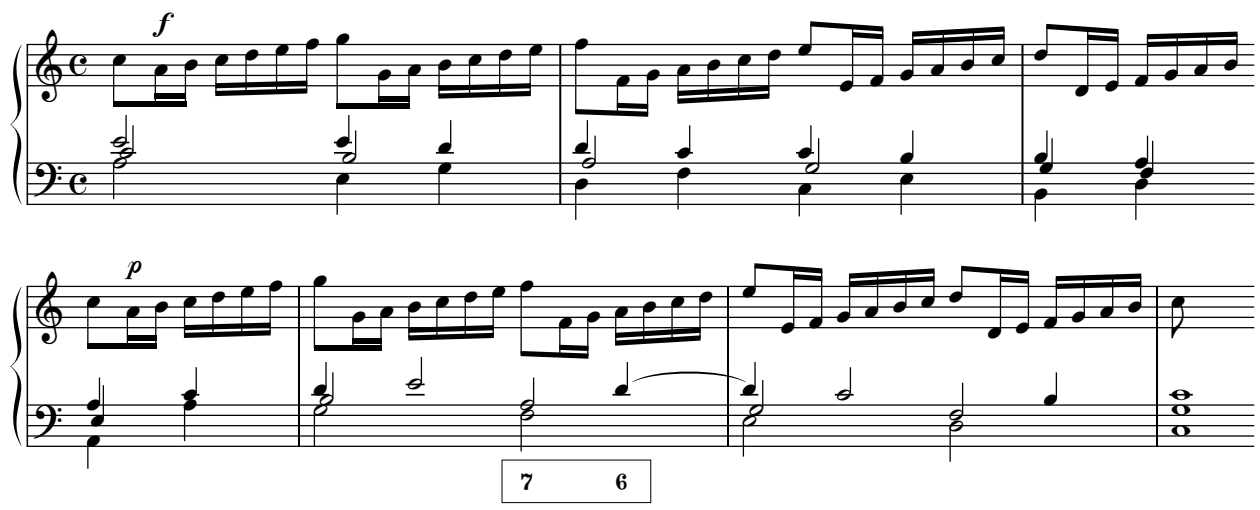

Beispiel 30: Jan Pieterszoon Sweelinck, Echo-Fantasie in d, T. 64-69 
Septimentiraten (bzw. Terzenketten im Septrahmen) bilden die Grundlage auch für die reicher diminuierten Oberstimmenkanons bei Lusitano (bzw. Picerli) und Cerreto (vgl. Beispiel 21, S. 35). In der Mehrzahl der Modelle läuft die Tirata (wie von Lusitano beschrieben) in Gegenbewegung zum übergeordneten sequenziellen Zug und entspricht somit einer Auskomponierung des jeweils übergeordneten Sekundschritts (bzw. dessen mittelbarer Höher- oder Tieferlegung).

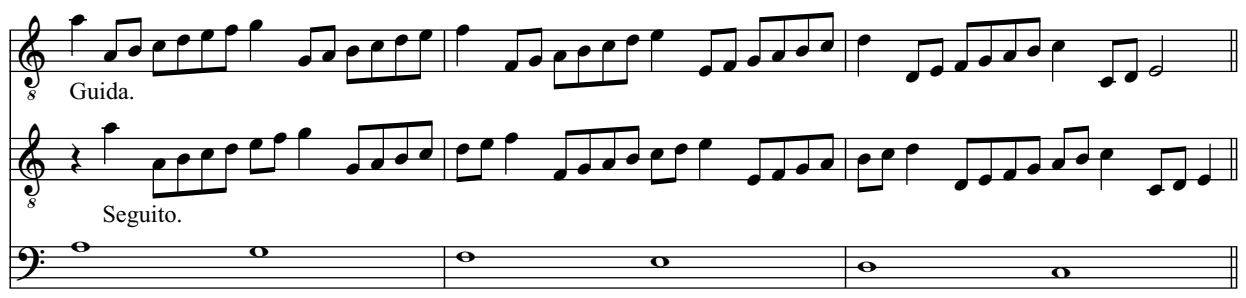

Beispiel 31: Zacconi 1622, 187 (= Cerreto 1601, 282), Ex. 2,3

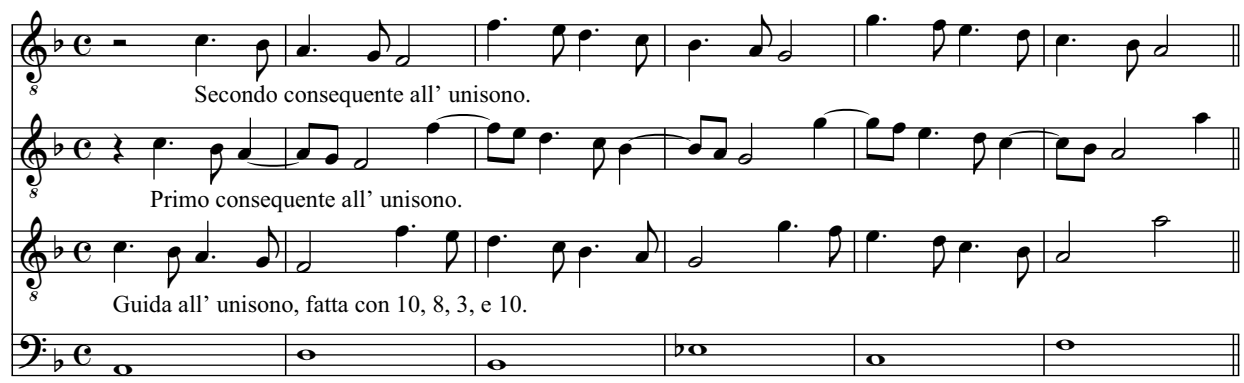

Soggetto ascendente per quarte

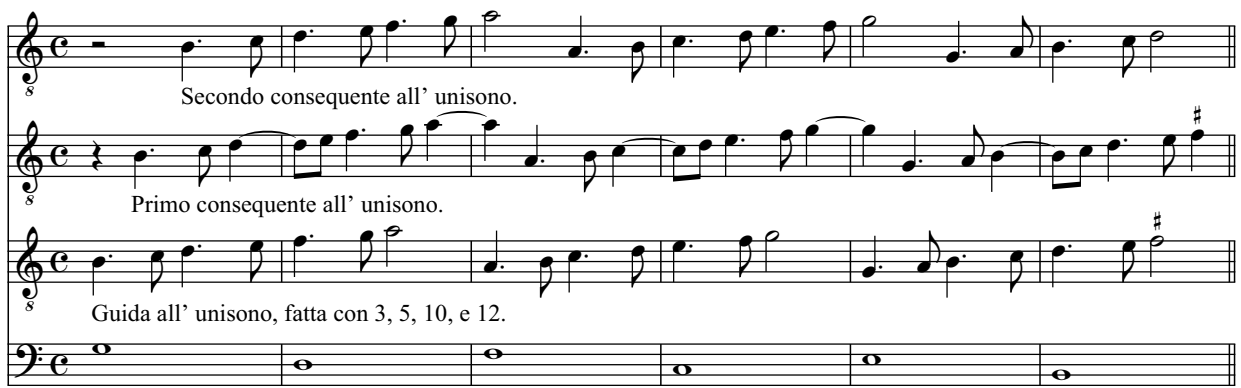

Soggetto discendente per quarte

Beispiel 32: Picerli 1630, 115 (vgl. Lusitano 1553, 19a, „Canto fermo per quarte [...] «, Abs. 1 und 3) 
Folgt hingegen die Septimentirata der übergeordneten Bewegungsrichtung, so bleibt das Verhältnis von Ausgangs- und Endton des Septrahmens ohne direkte Beziehung auf den sequenziellen Zug. Die Septime erweist sich dann als eine (im An- oder Auslaufen) diminutiv sgeweitete` Quinte, die im Gegenschritt den übergeordneten Sekundgang vermittelt.

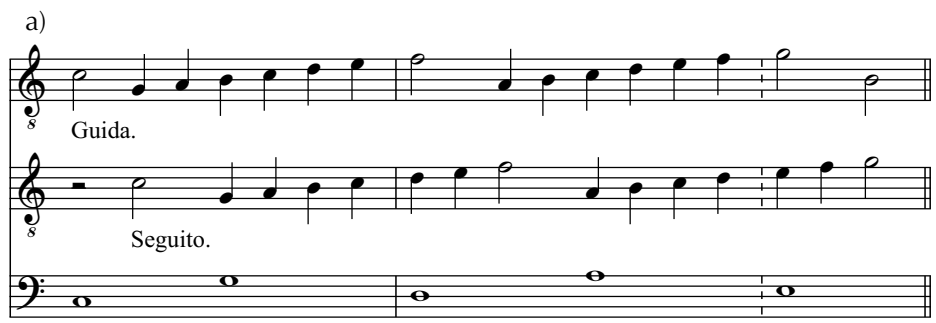

b)

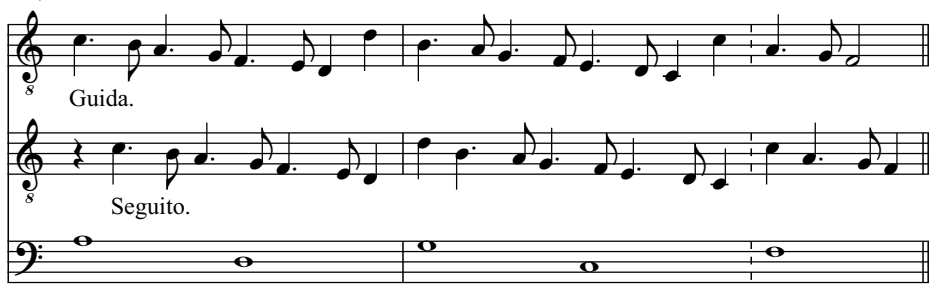

Beispiel 33: Zacconi 1622, 190 (= Cerreto 1601, 285): a) Ex. 7,2; b) Ex. 8,3

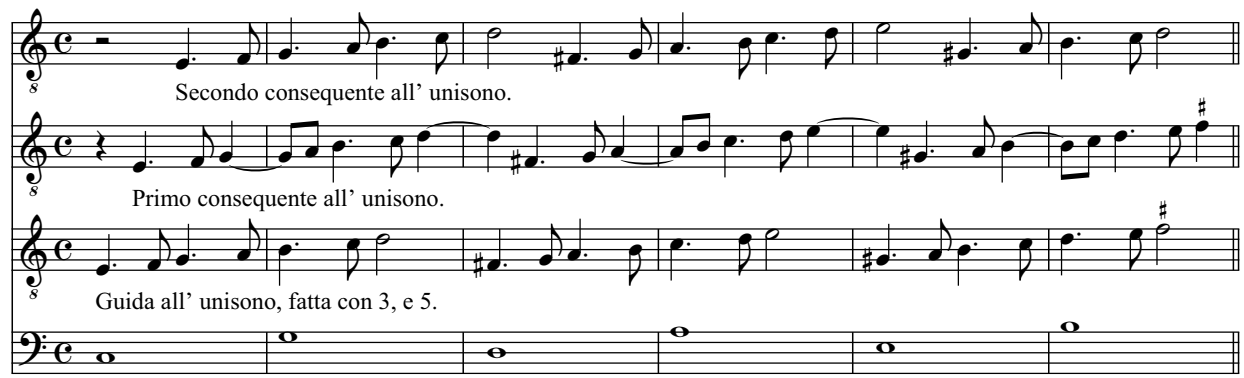

Soggetto ascendente per quinte.

Beispiel 34: Picerli 1630, 118 (vgl. Lusitano 1553, „Canto fermo per quinte [...]«, 20a, Abs. 2)

Reduktionen auf den jeweiligen Gerüstsatz `Note gegen Note nische Prinzip, in der führenden Kanonstimme die konstitutiven Quint- oder Quartprogressionen des Basses auf der Mixturebene zu verdoppeln (Parallelbewegung: Intervallfolge 3-3, Gegenbewegung: Intervallfolge 3-10). Für die Führung fortlaufend punktierter Skalen in komplementärrhythmisch nachschlagenden Unisoni, wie sie Picerlis dreifache Kanons kennzeichnet, gibt Sweelinck in seinen Composition Regeln ein schönes Beispiel 
(»Exempel, wie man das Unisonum soll gebrauchen «). ${ }^{91}$ Die Kanonimprovisation nach diesem Muster lehrt noch Berardi. ${ }^{92}$

Die Renaissance passagierender Improvisationsmodelle um 1600 korreliert auffällig mit der Transformation der »Alla-breve-Polyphonie« des 16. Jahrhunderts in die »konzertante Polyphonie « des frühen 17. Jahrhunderts: ${ }^{93}$ Imitatorisch-konzertierende Kadenzvorfelder aus Werken von Monteverdi und Schein bezeugen beispielhaft die kompositorische Relevanz der alten Modelle (vgl. Beispiele 31 und 32, S. 42)

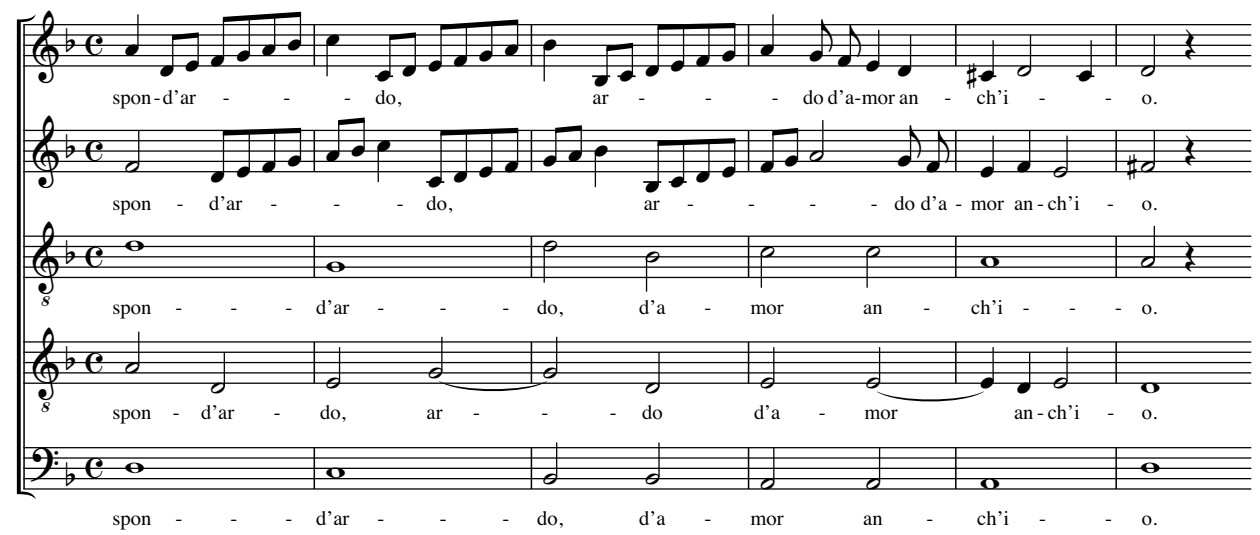

Beispiel 35: Claudio Monteverdi, Quell'augellin che canta (4. Madrigalbuch), T. 39-44

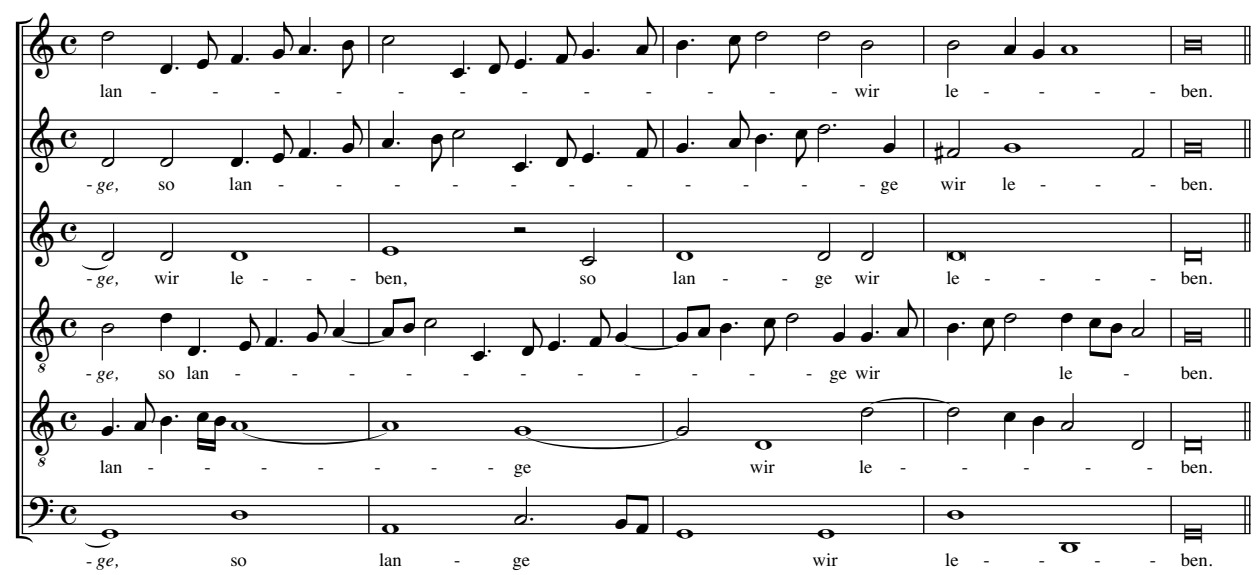

Beispiel 36: Johann Hermann Schein, Nu danket alle Gott (Israelsbrünnlein), T. 62-66

91 Sweelinck 1901, 28, § 79.

92 Berardi 1687, 109.

93 Vgl. Braun 1982, 69f. (zum Verhältnis von Gesangsimprovisation und Vokalconcerto) sowie 71 (zum Verhältnis von Alla-breve-Polyphonie und konzertierendem Stil). 


\section{Stilwandel}

Die Kritik, die Vicentino 1555 gegen einige der von ihm referierten Modelle vorbrachte, sie ermüdeten den Zuhörer durch die Wiederholung der immer gleichen Konsonanzen und Fortschreitungen, scheint weniger spezifischen Eigenschaften der konkreten Modelle zu gelten als vielmehr dem Sequenzprinzip an sich und dem (im improvisierten Kontrapunkt beinahe unvermeidlichen) Verstoß gegen das seit Tinctoris formulierte Gebot der vvarietası ${ }^{94}$ Aus Vicentinos Kritik lässt sich zugleich eine Distanz zu entsprechenden Kompositionspraktiken der Generation Josquins herauslesen: Gemessen am «klassizistischen Ideal einer vollständig ausbalancierten und fließenden Vokalpolyphonie musste das von Josquin so reichlich gebrauchte Mittel der rhetorisch insistierenden redictar unmodern erscheinen. Gerade die salten`, auf Wiederholung und Modellgebrauch beruhenden Techniken werden gegen Ende des 16. Jahrhunderts als Mittel sowohl des `Ausdrucks als auch der blockhaften Formgestaltung wiederentdeckt, nachdem sie zuvor in die Sphäre der sich erst etablierenden Instrumental- und Tastenmusik rabgesunken waren - ein kompositionsgeschichtlicher Brückenschlag, den Silke Leopold beispielhaft an Monteverdis sechsstimmiger Parodiemesse In illo tempore von 1610 festmacht. ${ }^{95}$

Worin aber bestand (auf einer satztechnisch beschreibbaren Ebene) das Neue im Gebrauch der alten Modelle? Die angestammten Orte melodischer wie kontrapunktischer Sequenzen waren bei Josquin Kontrapunktierungen linearer bzw. sequenzieller Cantus-firmus-Abschnitte sowie Kadenzvorfelder und Finalkontexte. Für die Eröffnung eines Satzabschnitts hingegen mit der Durchimitation einer sequenziellen $>$ fantasia ${ }^{96}$ finden sich im 16. Jahrhundert nur wenige Beispiele. Erst um die Jahrhundertwende wird die sequenzielle Faktur regelmäßig zur Grundlage formbildend gestalteter Imitationsabschnitte: Die imitatorische Faktur des Vordergrundes elaboriert die im Hintergrund gewissermaßen präexistente ıfantasia und splittet sie imitatorisch auf, so dass die realen Stimmen sukzessive in die kontinuierlich fortlaufende Sequenz eintreten (Beispiel 37, S. 46).

$94 »[\ldots]$ quel modo di fugare per sesta \& quinta non hà varietà alcuna, ne di consonanze, ne di gradi; per che il constante ripresenta all' oditore sempre le medisime consonanze ante dette con quelli gradi medisimi, \& tal modo no si dè usare, si per le ragioni sopra dette, come che è tanto commune à ogniuno, \& non è moderno [...] « (Vicentino 1555, IV, Kap. 23, 80). Sinngemäß äußert sich Vicentino auch zu Sequenzen aus Quart-Terz-Gegenschritten und zur Praxis des Dezimensatzes.

95 »Und doch gelingt es Monteverdi, die Soggetti Gomberts selbst im strengen Satz auf Möglichkeiten für seine bevorzugten Kompositionstechniken abzuklopfen: die Sequenz und die Ostinato-Technik - beides Satzarten, die in der Palestrina-Schule verpönt, in der Generation vor Palestrina, bei Gombert selbst und bei seinem Lehrer Josquin jedoch sehr beliebt waren." (Leopold 1993, 201)

96 Zum Gebrauch des Begriffes sfantasia im Sinne einer »kurzen kontrapunktischen Formel« (»a short contrapuntal formula«) vgl. Butler 1974, 602. 


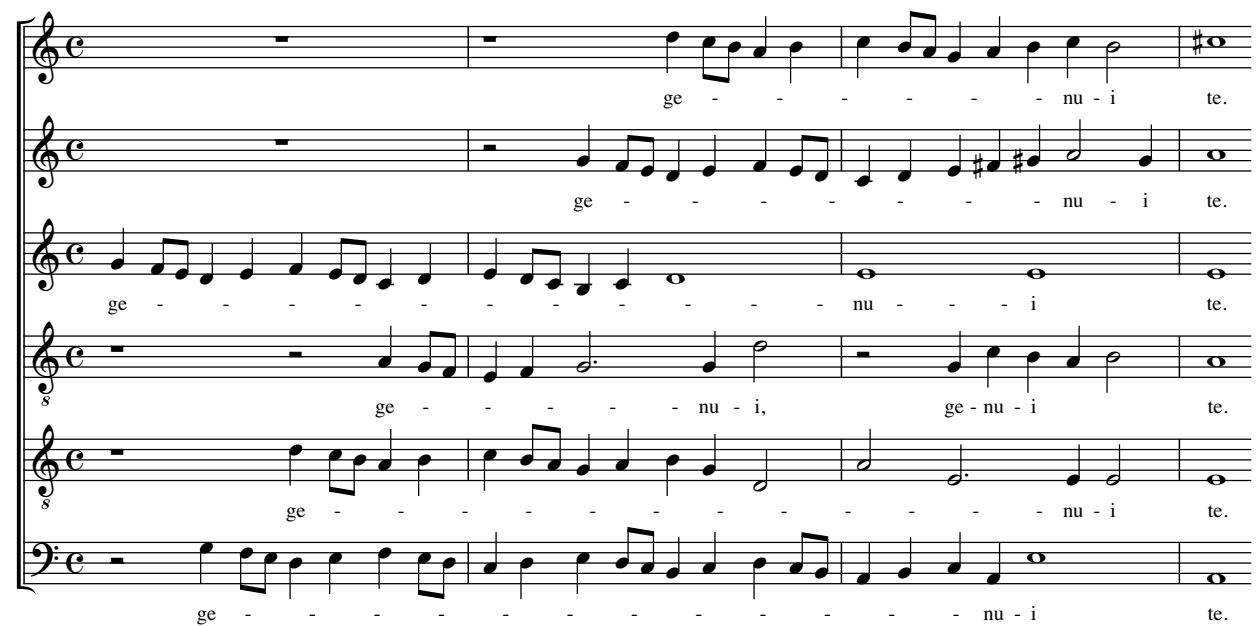

Beispiel 37: Claudio Monteverdi, Marienvesper, Dixit Dominus, T. 67-70

Die kanonische Formulierung des Modells ist in dieser Rhythmisierung strukturell auf vier Stimmen beschränkt: An den zweistimmigen Gerüstsatz des Unterstimmenpaares heften sich die Mixturen des Soprans II und des Alts. Durch die oktavversetzte Übernahme fortlaufender Sequenzstimmen generiert Monteverdi eine Abfolge von insgesamt sechs imitatorischen Einsätzen, die den Klangraum in die Höhe weiten. Das Verfahren ähnelt dem barocken Illusionismus vorgetäuschter Kuppelgewölbe, ohne jedoch (wie in der manieristischen Architektur) auf einer strukturellen Diskontinuität zu beruhen: Der ästhetische Mehrwert resultiert nicht aus einem `Bruch` zwischen Struktur und intendierter Wirkung, sondern aus der Inszenierung der hintergründigen Satzstruktur.

Momente solcher Inszenierung finden sich im kleinsten Detail. Die glanzvolle Überbietung der Satzoberstimme durch ihre imitatorisch in die Sequenz eintretende Oberterzmixtur etwa zielt ästhetisch nicht auf Struktur, sondern auf Klangwirkung: Die Verwandlung der Gerüststimme zur Klangkrone bringt den Satz zum Leuchten, während das Oberstimmenostinato in seiner insistierenden Statik zugleich eine Gegenspannung zur Dynamik des sequenziellen Zuges bildet (Beispiel 38).

Zu einer stilistischen Zweischichtigkeit führt vielfach die Auskomponierung vormals improvisierter Diminutionen und die Übernahme rhythmischer Modelle aus der Instrumental- und Tanzmusik in (ideell oder tatsächlich) generalbassgestützten Fakturen: So erhebt sich in Johann Hermann Scheins O Amarilli zart ein konzertierendes Oberstimmenduett mit modernen, syllabisch deklamierenden Auftaktfiguren (wie sie vor allem für das deutschsprachige Madrigal charakteristisch waren) über einem sakkordischen Synkopensatz des Unterchores, der sich in dieser Gestalt bis ins 15. Jahrhundert zurückverfolgen lässt (Beispiel 39). ${ }^{97}$

97 Zugleich veranschaulicht das Beispiel die Begrenzung von Kanons aus Terz-Sekund-Gegenschritten auf strukturelle Vierstimmigkeit. Schein ergänzt die bereits in Josquins Trauermusik (Beispiel 11, 


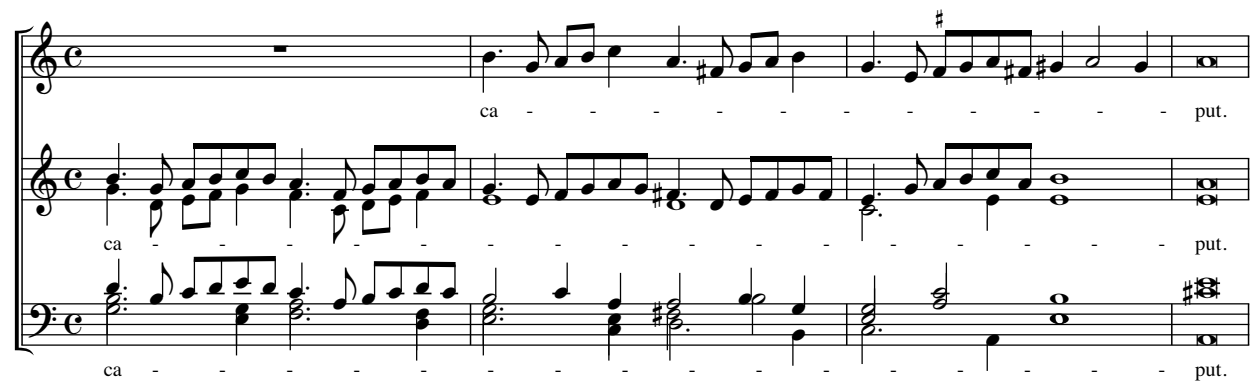

Beispiel 38: Claudio Monteverdi, Marienvesper, Dixit Dominus, T. 110-113

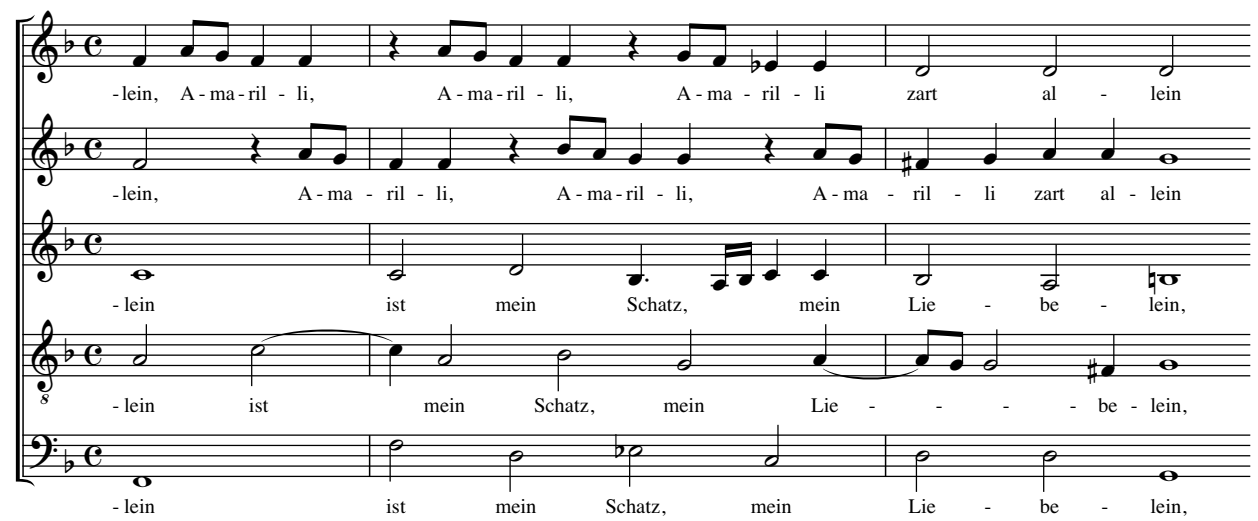

Beispiel 39: Johann Hermann Schein, O Amarilli zart (Diletti Pastorali Hirtenlust), T. 36 ff.

Weit über jene Wirkungen hinaus, die sich an satztechnischen Details oder kurzen Satzabschnitten festmachen lassen, prägt eine großflächig entfaltete (und dadurch formbildende) Zurschaustellung elementarer Satzgerüste gerade auch Monteverdis geistliche Musik, und hier nicht alleine die Marienvesper und die `Concertatos-Sätze etwa der Selva morale e spirituale, sondern, wie Silke Leopold bemerkt hat, auch die (nur scheinbar) retrospektiven Kompositionen `da cappellar. Monteverdis postum veröffentlichte vierstimmige Messe etwa präsentiert sich als ein regelrechter `Variationszyklus` über fallende Stufensequenzen auf Grundlage von Terz-Sekund-Gegenschritten: ${ }^{98}$ Formulierungen der 'fantasias in dichter Imitation finden sich ebenso wie skonzertantes Diminutionen, noematische Blöcke und madrigaleske Kontrapunktierungen fallender Basstetrachorde durch Gegenschritte in Akzentparallelen; Fakturen im Wechsel zwischen Grund- und Sextakkorden (quasi `Quintfallsequenzen`) stehen neben älteren Fakturen aus reinen Grundakkorden.

S. 29) beobachtete Faktur um eine fünfte Stimme (Alt), die den synkopierten Tenor strukturell verdoppelt und ihrerseits weder synkopiert noch volltaktig gesetzt werden kann: Einzig die auftaktige Formulierung mit vorhergehender Pause ermöglicht die fünfstimmige Ausarbeitung.

98 Vgl. Leopold 1993, 203. 
Die Fortschreibung oder Erneuerung älterer Modelle verändert diese zugleich, wie sich beispielhaft an verschiedenen Entwicklungsstufen des fallenden Quart-Terz-Gegenschritts ablesen lässt. ${ }^{99}$ Laut Braun beginnt die »Geschichte unserer Formel [...] im italienischen Madrigal des ausgehenden 16. Jahrhunderts «. ${ }^{100}$ Doch gehörte auch dieses für die ersten Jahrzehnte des 17. Jahrhunderts so charakteristische Modell bereits zum Repertoire des frühen 16. Jahrhunderts und findet sich etwa im Finalkontext von Josquins Gloria de beata virgine. ${ }^{101}$ Die von Josquin gewählte (im Detail nach Stimmenpaaren differenzierte) Rhythmisierung erlaubt drei zueinander verschobene Einsätze, zu denen der Sopran im Dezimensatz hinzutritt.

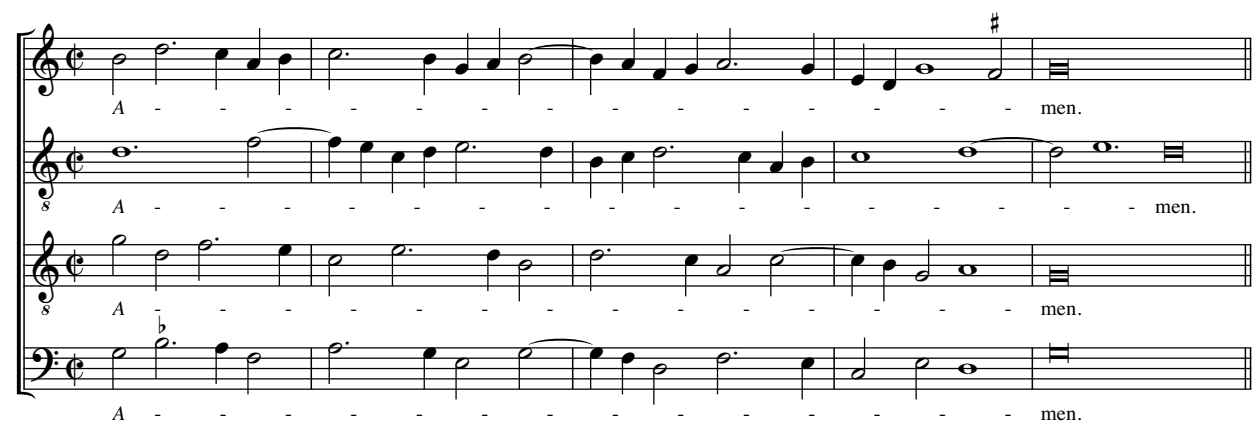

Beispiel 40: Josquin des Prez, Gloria de beata virgine, Finalkadenz

Eine mögliche Genese des Modells liegt in der Imitation der `Cambiaten`-Figur, deren charakteristisch aus der unteren Nebennote abspringende Terz in der zweiten Jahrhunderthälfte regelmäßig zum fallenden Sekundgang geglättet wurde. Auffallend häufig greift Monteverdi auf die herbere Urform zurück und nutzt gezielt ihr Potential als affektive Dissonanzenfigur.

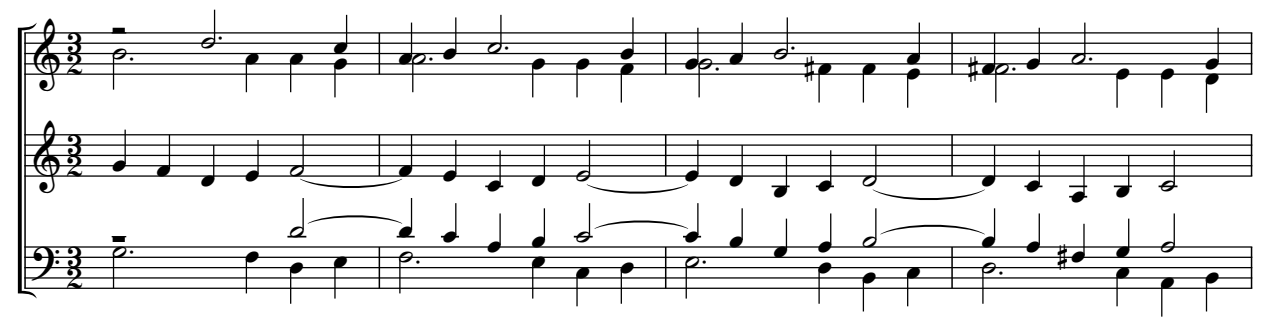

Beispiel 41: Claudio Monteverdi, L'Orfeo, 1. Akt, Ritornello, T. 296-299

99 Vgl. für den gesamten Zusammenhang Preuß 2002, 76 ff.

100 Braun 1982, 68. Braun verweist insbesondere auf die Ritornelle "zu Dixit Dominus der Marienvesper«, die »einen Abriß« der verschiedenen »Rhythmisierungsmöglichkeiten« des Modells bieten.

101 In den deutschen Quellen erscheint die Sequenz erstmals 1563 bei Dressler als Beispiel für Parallelen imperfekter Konsonanzen im zweistimmigen Dezimensatz $(1563,220)$. 
Gegen Ende des 16. Jahrhunderts wird das einstige `Cambiaten $-M o d e l l$ in einer zweizeitigen Rhythmisierung gebräuchlich. Das zweistimmige Kanongerüst Note gegen Note lässt sich, wie etwa Sweelinck demonstriert, beliebig austerzen oder auffüllen (Beispiel 42a). Sexten über den Penultimae der diminutiven Binnenzüge legen eine kadenzielle Interpretation nahe (im Sinne einer tenorisierenden und cantizierenden Vermittlung der Gegenschritte).

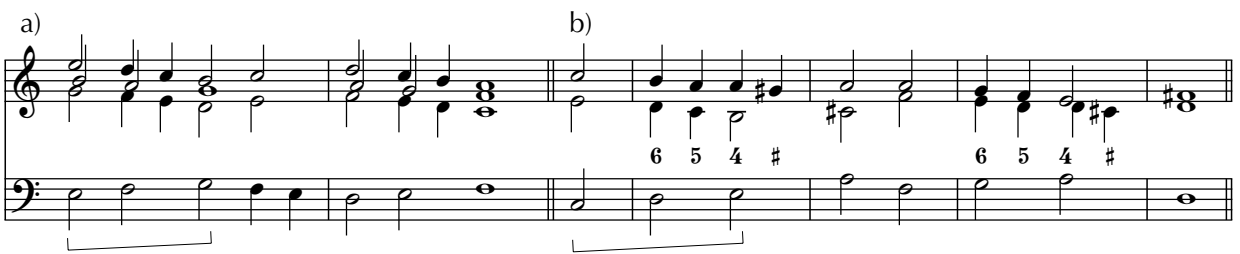

Beispiel 42: a) Sweelinck 1901, 27, § 78; b) Muffat 1699, 102, „Von der Cadentia majori«

Damit wird eine steigende, auf die V. Stufe (seltener auf die I. Stufe) gerichtete Bassformel (vgl. Beispiel 42b) zum Primärereignis, die sich in der zweiten Hälfte des 16. Jahrhunderts melodisch verselbständigt hatte. ${ }^{102}$ In Verbund mit fallender Chromatik vermögen die cantizierenden `Terzzüge` regelrechte Binnenkadenzen auszubilden.

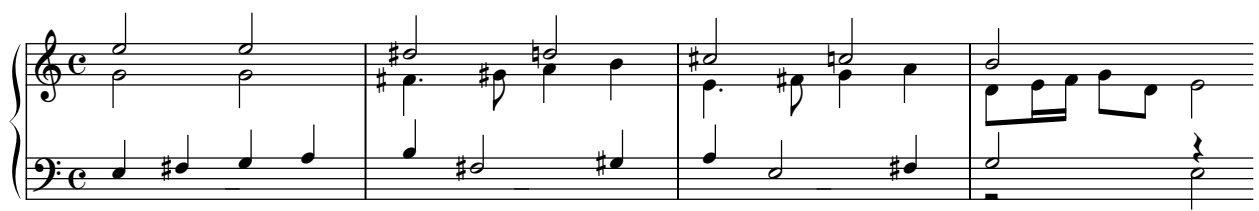

Beispiel 43: Jan Pieterszoon Sweelinck, Fantasia chromatica, T. 48-51

Die kadenziell vermittelnde Diminution der splagalen Progressionen $^{103}$, die aus dem melodischen Gegenschritt (fallende Quarte, steigende Terz) resultieren, ermöglichte ein Weiterleben entsprechender Modellvarianten bis ins frühe 18. Jahrhundert. Auch als Bassfundament unter einer Vorhaltskette blieb das sarchaische، Gegenschrittmodell (vor allem in der Tastenmusik) bis ins 18. Jahrhundert hinein gebräuchlich (Beispiel 44, S. 50).

In Fenarolis Regole von 1775 (die ansonsten streng der jahrhundertealten Systematik sequenzieller Bassprogressionen folgen) fehlt das Lieblingsmodell der Generation Monteverdis ganz: Es war mittlerweile der Dominanz von Quintschrittsequenzen und `DurMoll-Parallelismen` zum Opfer gefallen und harrte seiner historisierenden Wiederbelebung im 19. Jahrhundert.

102 Vgl. Dahlhaus 1968, 135.

$103 \mathrm{Vgl}$. die übergeordneten `Akkordfolgen in den Beispielen 42a (e-G-d-F) und 43 (e-H, D-A, C-G). 


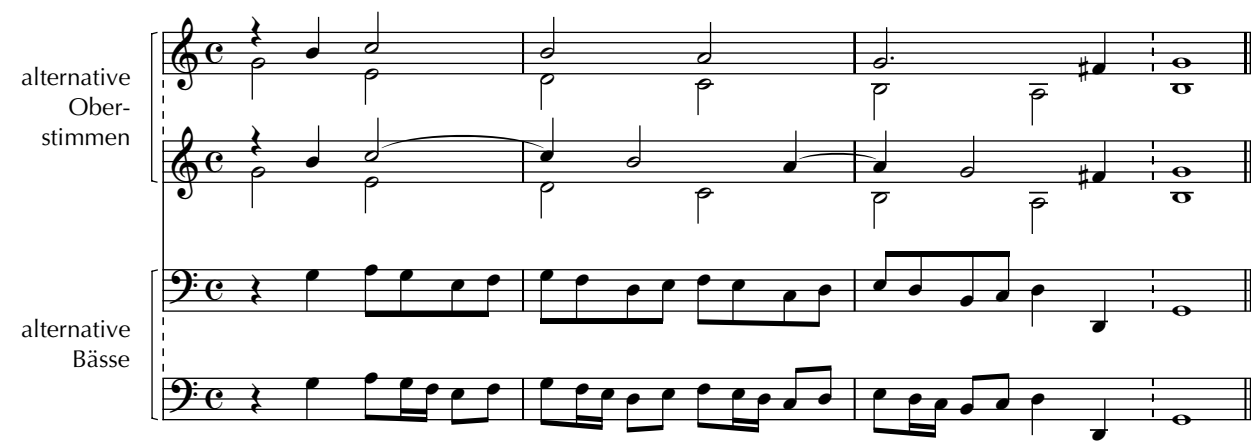

Beispiel 44: nach Murschhauser 1721, 103

Ein wesentlicher Aspekt der Erneuerung und Transformation von Modellen bestand, so viel dürfte deutlich geworden sein, in einer bis ins 18. Jahrhundert fortschreitenden Kadenzintegration: Die Diminution von Gegenschritten durch kadenziell vermittelnde Linienzüge weist ebenso in diese Richtung wie der zunehmende Gebrauch von Vorhaltsketten. Kadenzielles Potential bargen überdies die undiminuierten Progressionen sper quartam` oder >quintam`sowie der Terz-Sekund-Gegenschritt. ${ }^{104}$ Gewiss sind die Quintschritte der Sequenzmodelle des 16. Jahrhunderts nicht einfach sidentisch seln, doch korrelieren Stimmführungsmuster von Klauseln und Sequenzgliedern so weitgehend, dass es nur allzu nahe lag, sequenzielle Gänge kadenziell zu finalisieren ${ }^{105}$ und Binnenprogressionen (etwa durch Diskantklauselsignen über der Quintschritt-Penultima) kadenziell zu profilieren. Auch stand für Verkettungen der Synkopendissonanz seit Zarlinos ssfuggir la cadenzas ein ausbaufähiges kadenzielles Paradigma bereit ${ }^{106}$, das indes bis ins 18. Jahrhundert hinein nicht explizit auf Progressionen des Contrapunctus simplex übertragen wurde. ${ }^{107}$ Die Rede von $»$ Fundamentschrittmodelle[n] ${ }^{108}$ in Kompositionen des frühen 16. Jahrhunderts lässt sich bei allem Anachronismus also auch als Hinweis auf einen entwicklungsgeschichtlichen Zusammenhang verstehen.

\section{Vgl. Dahlhaus 1956, $91 \mathrm{f}$.}

105 In dem oben zitierten Satzabschnitt aus Scheins Amarilli (Beispiel 39, S. 47) geht die syntaktische Schließung des Zuges beispielhaft aus dem letzten Sequenzglied hervor.

106 Wenn etwa Dressler in den Klauseln eine Quelle für die »inventione fugarum « erkennt $(1563,243$; vgl. Herbst 1643, 94), so bedeutet dies nichts anderes, als dass die Klauselprogression losgelöst von ihrer syntaktischen Funktion zu einem frei verfügbaren Baustein der Satztechnik wird. Spätestens seit Berardi galt es als selbstverständlich, Verkettungen und Verschränkungen von Vorhalten als Fügungen vermiedener Synkopenklauseln zu verstehen oder zumindest die »Verwandschafft» der „Clausulae formales [...] mit denen Syncopationibus oder Bindungen « (Werckmeister 1702, 50, § 90) zu betonen. Konsequenterweise beruht auch Rameaus Theorie auf der »Vorstellung, daß Akkorde, um einen Zusammenhang zu bilden, durch Dissonanzen verkettet sein müssen. (Dahlhaus 1968, 22)

107 Dem jüngeren Paradigma sequenzieller Kadenzverkettung (demzufolge die Sequenz aus dem vorgeordneten Kadenzvorgang erwächst) stellt Jans die Beobachtung entgegen, in der Musik des 16. Jahrhunderts könnten verschiedene "Schlußvarianten rückwirkend die Logik der Klangfortschreitung beeinflussen.« $(1992,172)$

108 Vgl. Fladt 2005, 359. 


\section{Resümee}

Mit Fauxbourdonvarianten, (Vor-)Formen des >Dur-Moll-Parallelismus ${ }^{109}$, Gegenschritten und Klauseln sowie Techniken der Klauselimperfektion und -verschränkung standen Musikern des 16. Jahrhunderts `Modellkomplexe` zur Verfügung, die in der ıfuga elaboriert werden konnten. ${ }^{110}$ Der theoriegeschichtliche Ort des Modells (ausgenommen die artifizielleren Aspekte der Klauselbildung) war die Lehre vom Contrapunto alla mente, die zugleich auch Aspekte der kompositorischen Praxis reflektierte und instruierte: Die Modelle der Vokalimprovisation vermittelten zwischen der sukzessiven, vom zweistimmigen Gerüstsatz ausgehenden Kompositionsweise und der strukturellen Simultanität des vollstimmigen Satzes. ${ }^{111}$ Erst um 1600 jedoch wurde die Inszenierung von Modellen (und damit die strukturelle Zwei- oder Mehrschichtigkeit des Satzes) zu einem zentralen kompositionstechnischen und ästhetischen Paradigma: Etwas überpointiert ließe sich sagen, erst mit dieser Verschiebung seien die Modelle des 15. und 16. Jahrhunderts izu sich selbst gekommen. Die Umwertung der sfantasia` von einer handwerklichen Kategorie zu einer ästhetischen spiegelt sich in der Emanzipation der Sequenz. ${ }^{112}$ Anknüpfen konnte diese Entwicklung an antizipierende Tendenzen der Instrumentalmusik ebenso wie an ältere ırediktenfreudige` Kompositionspraktiken um 1500, die in der Praxis des Contrapunto alla mente lebendig geblieben waren. Überdies mag auch die praxisbezogene Ausbildung von sSänger-Komponisten ‘ anhand einer sequenzbasierten Improvisationsund Gesangsdidaktik in die kompositorische Praxis ausgestrahlt haben.

Die von der spätmittelalterlichen Gradus-Lehre bis ins 18. Jahrhundert reichende Traditionslinie eines auf Skalen- und Gegenschrittmodellen beruhenden Contrapunto alla mente erweist sich als ein theoriegeschichtlicher ımissing linkı: Kaum sonst in musiktheoretischen Zeugnissen, Traktaten und Lehrbüchern wird die entwicklungsgeschichtliche Kontinuität von der Vokalpolyphonie des 15. und 16. Jahrhunderts zum »ornamentalmodellhaften ${ }^{113}$ Kontrapunkt des `Generalbasszeitalters« so deutlich. Eingehender auf

109 Entsprechende ‘Bassfundierungen` des Gymel thematisiert bereits Guilielmus (1965, Kap. 6, 40); einen entwicklungsgeschichtlichen Abriss des Modells gibt Dahlhaus, der auch den (für das 16. Jahrhundert anachronistischen) Terminus des >Dur-Moll-Parallelismus` prägte (1968, 87 f. sowie 92).

110 Bereits im 16. Jahrhundert wurde der Zusammenhang von ıfuga`, sfantasia` und `locus communis` thematisiert. Dahlhaus kommentiert entsprechende Passagen in Claudio Sebastianis Bellum musicale von 1563: „Der scheinbare Widerspruch zwischen der Verknüpfung des Begriffs `Fantasiaく mit der sstrengen Imitationstechnik einerseits und der sfreien ‘ Improvisation und ‘Erfindungsgabe des Autors andererseits [...] verschwindet, wenn man bedenkt, daß sowohl die Improvisation als auch die Imitation in Engführung an ein begrenztes Repertoire melodischer und satztechnischer Formeln gebunden war und daß ,Erfindung`(Invention) nichts anderes als das Verfügen über solche Topoi bedeutete.« $(1960,204)$

111 »Bei der gedanklichen Ausarbeitung eines Satzes konnten Komponisten auch auf ihre Übung im Singen super librum zurückgreifen [...]«(Helms 2001, 16).

112 Das Verhältnis von Sequenz und Imitation brachte Mauritius Vogt auf den Punkt, indem er postulierte, "alle Themen oder Subjekte, die für Fugen geeignet sind «, seien ableitbar (deducuntur) »aus einfachen Fantasien« $(1719,154)$. Diese scheint Vogt sich durchweg als Sequenzen vorgestellt zu haben: Eine knappe Übersicht gebräuchlicher »phantasijs simplicibus« beinhaltet ausschließlich Gegenschrittmodelle und Vorhaltsketten.

113 Preuß 2002, 82. 
formal-syntaktische und semantische Kontexte des Modellgebrauchs einzugehen, bedürfte detaillierter Einzelanalysen, denen eine weitere Grundlage zu geben eine Absicht der vorliegenden Untersuchung ist.

\section{Literatur}

\section{Quellen}

Aaron, Petrus (1516), De Institutione harmonica, Bonn, Reprint New York: Broude Bros. 1978.

Banchieri, Adriano (1614), Cartella musicale nel canto figurato fermo, \& contrapunto, Venedig, Reprint Bologna: Forni 1968 (= BMB II/26).

Berardi, Angelo (1687), Documenti armonici, Bologna, Reprint Bologna: Forni 1970 (= BMB II/40a).

— (1698), Miscellanea musicale, Bologna, Reprint Bologna: Forni 1970 (= BMB II/40b).

Buchner, Hans (1525), »Fundamentum, sive ratio vera«, Ms., hg. von Harro Schmidt in: Hans Buchner, Sämtliche Orgelwerke, Bd. 1 (= EdM 54), Frankfurt a.M.: Litolff 1974.

Cerone, Pedro (1613), El melopeo y maestro, Neapel, Reprint Barcelona: Consejo superior de investigaciones científicas 2007.

Cerreto, Scipione (1601), Della prattica musica vocale et strumentale, Neapel, Reprint Bologna: Forni 1969 (= BMB II/30).

Diruta, Girolamo (1593), Il Transilvano, Venedig, Reprint Bologna: Forni 1997 (= BMB II/132).

Dressler, Gallus (1563), »Praecepta musicae poeticae«, Ms. Magdeburg, hg. von Bernhard Engelke, Geschichtsblätter für Stadt und Land Magdeburg 49/50 (1914/15), 213-250.

Fenaroli, Fedele (1775), Regole musicali di cembalo, Neapel, Reprint Bologna: Forni 1975 (= BMB II/140).

Grampp, Florian (Hg.), (2006), Deutsche Gesangstraktate des 17. Jahrhunderts. Daniel Friderici, Johann Andreas Herbst, Johann Crüger (= Documenta Musicologica I/43), Kassel u. a.: Bärenreiter.

Guilielmus monachus (1965), De preceptis artis musice et pratice compendiosus libellus, Ms., hg. von Albert Seay, Rom: American Institute of Musicology (= CSM 11).

Herbst, Johann Andreas (1643), Musica poetica, sive Compendium melopoëticum [...], Nürnberg, Mikrofiche, Leiden: IDC.

Hothby, Johannes (1977), De arte contrapuncti, Ms., hg. von Gilbert Reaney, Neuhausen-Stuttgart: American Institute of Musicology/Hänssler (= CSM 26).

Kircher, Athanasius (1650), Musurgia universalis, 2 Bde., Rom, Reprint Hildesheim u.a.: Olms 1970. 
Lusitano, Vincenzo (1553), Introduttione facilissima et novissima di canto fermo, figurato, contrapunto semplice, et in concerto, Rom, Reprint d. Ausg. Venedig 1561, Lucca: Libreria Musicale Italiana 1989 (= Musurgiana 7).

Marpurg, Friedrich Wilhelm (1753/54), Abhandlung von der Fuge [...], 2 Bde., Berlin, Reprint Hildesheim u. a.: Olms 1970.

Muffat, Georg (1699), »Regulae concentuum partiturae«, Ms., hg. von Hellmut Federhofer als: An Essay on Thoroughbass (= Musicological Studies and Documents 4), American Institut of Musicology 1961.

Murschhauser, Franz Xaver Anton (1721), Academia musico-poetica bipartita [...], Nürnberg, Mikrofiche, Leiden: IDC.

Paumann, Conrad (1452), »Fundamentum organisandi«, Ms. Nürnberg, Reprint in: Das Lochheimer Liederbuch nebst der Ars organisandi von Conrad Paumann, hg. von Friedrich Wilhelm Arnold, Leipzig: Breitkopf \& Härtel 1926.

Picerli, Silverio (1630), Specchio seconda di musica, Neapel (Bibliothèque nationale de France).

Praetorius, Friedrich Emanuel (1961), »Exempla auf den Bassum Continuum«, Ms. Lüneburg zw. 1655 u. 1695, hg. von Joachim Birke als: »Friedrich Emanuel Praetorius' `Exempla auf den Bassum Continuum«", Mf 14, 370-393.

Rodio, Rocco (1609), Regole di musica, Neapel, Reprint Bologna: Forni 1981 (= BMB II/56).

Santa María, Tomás de (1665), Libro Llamado arte de taner fantasía, Valladoid, Reprint Barcelona: Consejo superior de investigaciones científicas 2007.

Scaletta, Oratio (1600), Scala di musica molto necessaria per principianti, Venedig, Reprint d. Ausg. Venedig 1626, Bologna: Forni 1976 (= BMB II/33).

Spiridionis a Monte Carmelo (1670/71/75), Nova instructio pro pulsandis organis, spinettis, Manuchordiis, 4 Bde., Bamberg 1670, 1671; Würzburg 1675, Reprint hg. von Edoardo Bellotti, Colledara: Andromeda 2003.

Sweelinck, Jan Pieterszoon (1901), Composition Regeln, Ms., hg. von Hermann Gehrmann, 's-Gravenhage/Leipzig (= Werken van Jan Pieterszn. Sweelinck 10)

Tigrini, Orazio (1588), Il compendio della musica nel quale brevemente si tratta dell'arte del contrapunto, Venedig, Reprint New York: Broude Bros. 1966.

Urbevetani, Ugolini (1960), Declaratio musicae disciplinae, II. Buch, Ms., hg. von Albertus Seay, Rom 1960: American Institute of Musicology (= CSM 7).

Vicentino, Nicola (1555), L'antica musica ridotta alla moderna prattica, Rom (Bibliothèque nationale de France).

Vogt, Mauritius (1719), Conclave thesauri magnae artis musicae [...], Prag, Mikrofiche, Rochester, NY: Sibley Music Library.

Werckmeister, Andreas (1702), Harmonologia musica, Frankfurt/Leipzig, Reprint Hildesheim u. a.: Olms 1994.

Zacconi, Lodovico (1622), Prattica di musica, Bd. 2, Venedig, Reprint Bologna: Forni 1967 (= BMB II/2).

Zarlino, Gioseffo (1573), Le Istitutioni harmoniche, Venedig, Reprint New Jersey: Ridgewood 1966. 
Apel, Willi (1967), Geschichte der Orgel- und Klaviermusik bis 1700, Kassel u. a.: Bärenreiter.

Apfel, Ernst (1981), Geschichte der Kompositionslehre von den Anfängen bis gegen 1700, 3 Bde., Wilhelmshaven: Heinrichshofen's.

Braun, Werner (1982), Der Stilwandel in der Musik um 1600, Darmstadt: Wissenschaftliche Buchgesellschaft.

(1994), Deutsche Musiktheorie des 15. bis 17. Jahrhunderts, Teil II, von Calvisius bis Mattheson (= GMth 8/II), Darmstadt: Wissenschaftliche Buchgesellschaft.

Butler, Gregory G. (1974), »The Fantasia as Musical Image«, The Musical Quarterly 60/4, 602-615.

Bandur, Markus (2002), Artikel »Improvisation, Extempore, Impromptu«, in: HmT 32.

Dahlhaus, Carl (1956), „Versuch über Bachs Harmonik«, Bach-Jb. 43, 73-92.

(1959), „Formen improvisierter Mehrstimmigkeit im 16. Jahrhundert», Musica 13, 163-167.

_ (1960), »Besprechung von: Alfred Mann, The Study of Fugue», Mf 13, 224-244.

(1968), Untersuchungen über die Entstehung der harmonischen Tonalität, Kassel u. a.: Bärenreiter.

(1978), „»Neue Musikı als historische Kategorie», in: Schönberg und andere. Gesammelte Aufsätze zur Neuen Musik, Mainz: Schott, 29-39.

(1984), Die Musiktheorie im 18. und 19. Jahrhundert, Teil 1, Grundzüge einer Systematik (= GMth 10), Darmstadt: Wissenschaftliche Buchgesellschaft.

Deppert, Heinrich (1993), Kadenz und Clausel in der Musik von J.S. Bach. Studien zu Harmonie und Tonart, Tutzing: Hans Schneider.

Federhofer, Hellmut (1981): Akkord und Stimmführung in den musiktheoretischen Systemen von Hugo Riemann, Ernst Kurth und Heinrich Schenker (= Veröffentlichungen der Kommission für Musikforschung der österreichischen Akademie der Wissenschaften 21), Wien: VÖAW.

Fladt, Hartmut (2005), »Modell und Topos im musiktheoretischen Diskurs", Musiktheorie 20, 343-369.

Froebe, Folker (i. V.), »Kanonmodelle `Note gegen Note` in der Musiktheorie des 18. Jahrhunderts", in: Musiktheorie und Vermittlung - Tagungsbericht des VI. Kongresses der Gesellschaft für Musiktheorie (GMTH), hg. von Klaus Heiwolt, Hildesheim u. a.: Olms.

Goldschmidt, Hugo (1892), Die italienische Gesangsmethode des XVII. Jahrhunderts und ihre Bedeutung für die Gegenwart, Breslau, Reprint Leipzig: Zentralantiquariat der Deutschen Demokratischen Republik 1978.

Groth, Renate (1989), »ltalienische Musiktheorie im 17. Jahrhundert«, in: Italienische Musiktheorie im 16. und 17. Jahrhundert. Antikenrezeption und Satzlehre (= GMth 7), Darmstadt: Wissenschaftliche Buchgesellschaft, 307-379. 
Gurlitt, Wilibald (1966), »Canon sine pausis«, in: Musikgeschichte und Gegenwart, Teil 1 (= BzAfMw 1), Wiesbaden: Franz Steiner, 105-110.

Helms, Dietrich (2001), »Denken in Intervallverbänden. Kompositionsdidaktik und Kompositionstechnik um 1500«, Mf 54, 1-23.

Jans, Markus (1986), »Alle gegen eine. Satzmodelle in Note-gegen-Note-Sätzen des 16. und 17. Jahrhunderts", Basler Jahrbuch für historische Musikpraxis 10, 101-120.

(1992), »Modale `Harmonikı. Beobachtungen und Fragen zur Logik der Klangverbindungen im frühen 16. und 17. Jahrhundert«, Basler Jahrbuch für historische Musikpraxis 16, 167-188.

Koldau, Linda Maria (2005), Die venezianische Kirchenmusik von Claudio Monteverdi, 2. Aufl. Kassel u. a.: Bärenreiter.

La Motte, Diether de (1981), Kontrapunkt. Ein Lese- und Arbeitsbuch, Kassel u.a.: Bärenreiter.

Laubenthal, Annegrit / Klaus-Jürgen Sachs (1989/90), »Theorie und Praxis«, in: Die Musik des 15. und 16. Jahrhunderts (= Neues Handbuch der Musikwissenschaft 3), Laaber: Laaber, 129-192.

Leopold, Silke (1993), Claudio Monteverdi und seine Zeit, 2. Aufl. Laaber: Laaber.

Loesch, Heinz von (2003), »Musica - Musica practica - Musica poetica», in: Deutsche Musiktheorie des 15. bis 17. Jahrhunderts, Teil 1 (= GMth 8/I), Darmstadt: Wissenschaftliche Buchgesellschaft.

Möllers, Christian (1989), »Analyse durch Improvisation. Chaconnebässe der Barockzeit als Improvisationsmodelle«, Üben und Musizieren 6, 73-86.

Preuß, Volkhardt (2002), „Die Fuge zwischen Rezeption und Wandel«, in: Melodie und Harmonie, Festschrift für Christoph Hohlfeld (= Musik und, Schriftenreihe der Hochschule für Musik und Theater Hamburg, Neue Folge 3), hg. von Reinhard Bahr. Berlin: Weidler, 63-84.

Rempp, Frieder (1989), „Elementar- und Satzlehre von Tinctoris bis Zarlino«, in: Italienische Musiktheorie im 16. und 17. Jahrhundert. Antikenrezeption und Satzlehre (= GMth 7), Darmstadt: Wissenschaftliche Buchgesellschaft, 39-220.

Riemann, Hugo (1929), Geschichte der Musiktheorie im 9.-19. Jahrhundert, Berlin, Reprint Hildesheim u. a.: Olms 1990.

Sachs, Klaus-Jürgen (1983), »Arten improvisierter Mehrstimmigkeit nach Lehrtexten des 14.-16. Jahrhunderts«, Basler Jahrbuch für Historische Musikpraxis 7, 166-183.

— (1984), „Die Contrapunctus-Lehre im 14. und 15. Jahrhundert«, in: Die mittelalterliche Lehre von der Mehrstimmigkeit (= GMth 5), Darmstadt: Wissenschaftliche Buchgesellschaft, 161-256.

Salzer, Felix / Carl Schachter (1969), Counterpoint in Composition, New York, Reprint Chichester (West Sussex): Columbia Press 1989.

Schubert, Peter (2002), „Counterpoint pedagogy in the Renaissance«, in: The Cambridge History of western Music Theory, hg. von Thomas Christensen, Cambridge University Press, 503-533. 